\title{
Force Analysis and Bubble Dynamics during Flow Boiling in Silicon Nanowire Microchannels
}

\author{
Tamanna Alam ${ }^{\mathrm{a}}$, Wenming Li ${ }^{\mathrm{a}}$, Fanghao Yang ${ }^{\mathrm{b}}$, Wei Chang ${ }^{\mathrm{a}}$, Jing Li ${ }^{\mathrm{c}}$, Zuankai Wang ${ }^{\mathrm{c}}$, Jamil \\ Khan ${ }^{\mathrm{a}}$, Chen $\mathrm{Li}^{\mathrm{a}}$,* \\ ${ }^{a}$ Department of Mechanical Engineering, University of South Carolina, Columbia, SC, 29210, \\ United States \\ ${ }^{b}$ IBM Research, IBM T. J. Watson Research Center, Yorktown Heights, NY 10598, United States \\ ${ }^{c}$ Department of Mechanical and Biomedical Engineering, City University of Hong Kong, Hong \\ Kong, China
}

\begin{abstract}
In microchannel flow boiling, bubble nucleation, growth and flow regime development are highly influenced by channel cross-section and physical phenomena underlying this flow boiling mechanism are far from being well-established. Relative effects of different forces acting on wall-liquid and liquid-vapor interface of a confined bubble play an important role in heat transfer performances. Therefore, fundamental investigations are necessary to develop enhanced microchannel heat transfer surfaces. Force analysis of nucleating bubble and bubble dynamics in flow boiling Silicon Nanowire microchannels has been performed based on theoretical, experimental and visualization studies. The relative effects of different forces on flow regimes, instabilities and heat transfer performances of flow boiling in Silicon Nanowire microchannels have been identified. Inertia, surface tension, shear, buoyancy, and evaporation momentum forces have significant importance at liquid-vapor interface as discussed earlier by other researchers. However, no comparative study has been done for different surface properties till date. Detail analyses of these forces including contact angle effect, channel dimension effect, heat flux effect and mass flux effect in flow boiling microchannels have been conducted in this study. A comparative study between Silicon Nanowire and Plainwall microchannels has been performed based on force analysis in the flow boiling microchannels. Compared to Plainwall microchannels, enhanced surface rewetting and CHF are owing to higher surface tension force at liquid-vapor interface and Capillary dominance resulting from Silicon Nanowires. Whereas, low Weber number in Silicon Nanowire helps maintaining uniform and stable thin film and improves heat transfer performances. Moreover, results from these studies are compared with literature and great agreements have been observed.
\end{abstract}

\section{Keywords}

Silicon nanowire, Microchannel, Flow boiling, Surface tension force, Inertia force, Contact angle

*Corresponding author. Tel: +1 803777 7155; Email address: li01@cec.sc.edu 


\section{Nomenclature}

$A_{c} \quad$ Channel cross-sectional area, $\mathrm{m}^{2}$

$A_{i} \quad$ Bubble interface area, $\mathrm{m}^{2}$

$A_{p l} \quad$ Shear plane area, $\mathrm{m}^{2}$

Bo Bond number $\left(\left(\rho_{l}-\rho_{v}\right) \cdot g \cdot \cos \varphi \cdot D^{2} / \sigma \cdot \cos \theta\right)$

$\mathrm{Bl} \quad$ Boiling number $\left(q_{e f f}^{\prime \prime} / G . h_{l v}\right)$

$\mathrm{Ca}$ Capillary number $(\mu \cdot U / \sigma \cdot \cos \theta)$

$D \quad$ Relevant dimension, $\mathrm{m}$

$D_{h} \quad$ Channel hydraulic diameter, $\mu \mathrm{m}$

$d \quad$ Bubble diameter, $\mu \mathrm{m}$

$F_{b} \quad$ Buoyancy force, $\mathrm{N}$

$F_{i}$ Inertia force, $\mathrm{N}$

$F_{M} \quad$ Evaporation momentum force, $\mathrm{N}$

$F_{S} \quad$ Surface tension force, $\mathrm{N}$

$F_{\tau} \quad$ Shear force, $\mathrm{N}$

$G$ Mass flux, $\mathrm{kg} / \mathrm{m}^{2} \mathrm{~s}$

$g \quad$ Gravitational acceleration, $\mathrm{m} / \mathrm{s}^{2}$

$H \quad$ Channel height, $\mu \mathrm{m}$

$h \quad$ Heat transfer coefficient, $\mathrm{kW} / \mathrm{m}^{2} \mathrm{~K}$

$h_{l v} \quad$ Latent heat of vaporization, $\mathrm{kJ} / \mathrm{kg}$

$q_{\text {eff }}^{\prime \prime} \quad$ Effective heat flux, $\mathrm{W} / \mathrm{cm}^{2}$

$q_{E V}^{\prime \prime} \quad$ Evaporative heat flux at the interface, $\mathrm{W} / \mathrm{cm}^{2}$

Re Reynolds number $(\rho . U . D / \mu)$

$t$ Time, $\mathrm{s}$

$U \quad$ Fluid mean velocity, $\mathrm{m} / \mathrm{s}$

$V \quad$ Volume of bubble, $\mathrm{m}^{3}$

We Weber number $\left(\rho \cdot U^{2} \cdot D / \sigma \cdot \cos \theta\right)$

$x_{e} \quad$ Exit vapor quality

Greek symbols

$\alpha \quad$ Void fraction

$\delta \quad$ Film thickness, $\mu \mathrm{m}$

$\theta \quad$ Contact angle

$\rho \quad$ Fluid average density, $\mathrm{kg} / \mathrm{m}^{3}$

$\rho_{l} \quad$ Liquid density, $\mathrm{kg} / \mathrm{m}^{3}$

$\rho_{v} \quad$ Vapor density, $\mathrm{kg} / \mathrm{m}^{3}$

$\sigma$ Surface tension, $\mathrm{N} / \mathrm{m}$

$\mu \quad$ Fluid viscosity, $\mathrm{kg} / \mathrm{ms}$

$\varphi \quad$ Heating surface orientation 


\section{Introduction}

Flow boiling in microchannels is a highly efficient mode of heat transfer for a variety of applications including cooling high power microelectronics [1-3], compact heat exchangers, and chemical reactors [4-7]. In recent years, microscale flow boiling has been paid extensive attention due to its large surface to volume ratio, high heat transfer capacity, uniform temperature distribution and low mass flux requirements [8-10]. In spite of these positive attributes, flow boiling in microchannels encounters some major problems including flow instabilities, which degrades their reliability (non-uniform wall temperatures distribution, premature dry out, critical heat flux limitation and flow reversal) and heavy pressure drop penalty than its single-phase equivalent [8, 11-14]. Flow boiling instabilities can be controlled or mitigated by controlling flow regime development. A flow boiling cycle includes bubble nucleation, growth, separations, interactions, development of two-phase flow regimes and rewetting for a given channel geometry and working conditions; and these are primarily influenced by surface properties. A number of studies have been performed to enhance heat transfer in microchannels by controlling bubble nucleation site density and wettability via changing surface properties [15-17]. Artificial nucleation cavities were formed on the boiling surfaces to enhance nucleate boiling by various methods, such as micromachining [18-21], nanostructured surfaces [22-26], porous metal coating [27-29], and chemical etching [30, 31]. Recently, nanowires (NWs) [32, 33] and carbon nanotubes (CNTs) [34-36] were used to enhance nucleate pool boiling and convective boiling in microchannels [23, 25, 26, 34, 37, 38] and improved heat transfer coefficient and critical heat flux were reported owing to the higher nucleation site density and enhanced wettability. However, optimization of surface properties to control bubble size, forces acting on bubble and flow patterns/ regimes has not yet been well resolved.

Enhanced flow boiling performances and reduced instabilities can be achieved by controlling flow regime development without having large pressure drop penalties and introducing complex geometries as demonstrated in our previous studies [39-41]. A novel boiling surface with submicron pores formed by NW bundles and nanoscale pores created by individual NWs were developed by our team [39]. This Silicon Nanowire (SiNW ) microchannel configuration reduced the transitional flow boiling regimes in plainwall microchannels to a single annular flow starting from onset of nucleate boiling (ONB) to critical heat flux (CHF) conditions by controlling the flow structure in two aspects: reducing bubble size and transforming the direction of the surface tension force from the cross-sectional plane to the inner-wall plane [39-41]. An enhanced heat transfer, CHF and reduced pressure drop and instabilities were observed from these studies. Efforts have been made to understand the heat transfer mechanisms and other relevant problems including flow patterns, instabilities, and CHF etc on flow boiling occurring in SiNW microchannels. However, there are still many unexplained physical phenomena underlying the observed behaviors.

Understanding conjugated effects of various forces acting on bubble and liquid-vapor interface in SiNW microchannels are necessary to understand the flow boiling phenomena inside the 
channels and are also a key to develop enhanced heat transfer surfaces. A number of research efforts on flow boiling in microchannels were focused on understanding the underlying mechanisms [20, 42-47]. Recently, Kandlikar [48] provides excellent discussion on the effects of different forces acting on liquid-vapor interface and settles on the inertia, surface tension, shear, buoyancy, and evaporation momentum forces as the candidates for significance. Although there are a number of researches have been focused on the force analysis of bubble and liquid-vapor interface in microchannel flow boiling, the investigation of forces on SiNW microchannels including contact angle, channel dimension and operating conditions are still deficient to the best of the authors' knowledge. Moreover, validation of force analysis with experimental observations and literatures are also unavailable. The objective of this paper is to study the forces acting on the vapor bubble and liquid-vapor interface in flow boiling SiNW microchannels based on theoretical, experimental and visualization studies.

\section{Analysis of forces acting on a liquid-vapor (L-V) interface}

Inertia, surface tension, shear, buoyancy, and evaporation momentum forces are of significant importance at liquid-vapor interface and their relative effects of these forces play a major role in establishing different two-phase flow regimes in microchannels. Forces acting on a liquid-vapor interface of a bubble inside the microchannel are schematically shown in Fig.1. The normalized forces with respect to channel unit cross-sectional area are used to understand the relative effects of these forces over bubble behaviors. Adopting simplified equations from Kandlikar [48] and incorporating static contact angle and heating surface orientation, forces are calculated in this study.

(a)

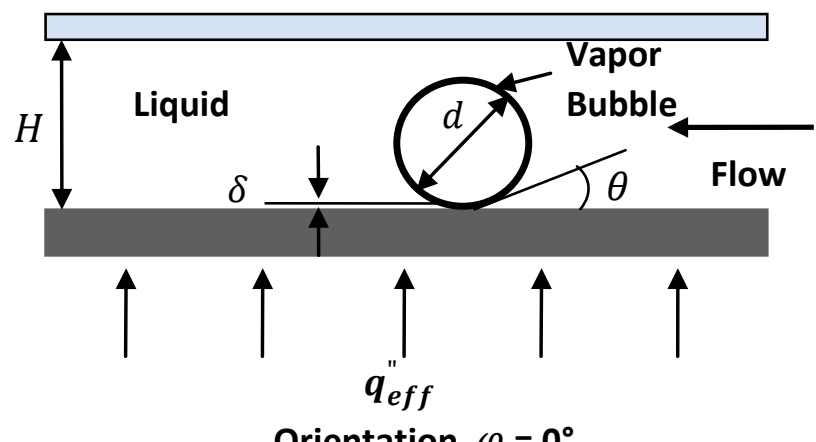

(b)

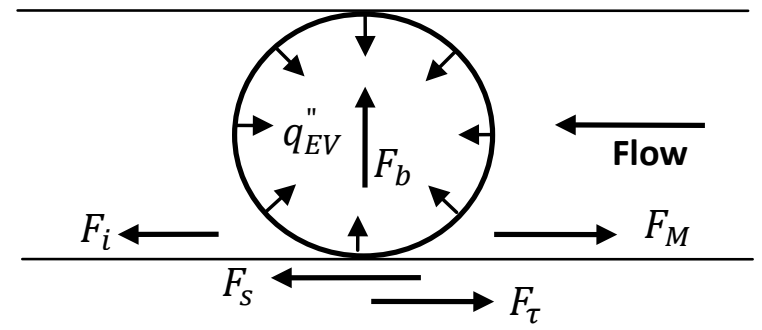

Fig.1. Forces acting on a liquid-vapor interface of a growing bubble in a microchannel crosssection. 
The surface tension force is expressed as,

$$
F_{s}=\sigma \cdot \cos \theta \cdot D
$$

where, $\sigma$ is the surface tension, $\theta$ is the contact angle and $D$ is the relevant dimension. Surface tension force per unit area,

$$
F_{S}^{\prime \prime}=\frac{\sigma \cdot \cos \theta \cdot D}{A_{c}}
$$

where, $A_{c}$ is the channel cross-sectional area.

Surface tension force, $F_{s}$ acts at the liquid-vapor interface across the channel cross-section and pulls liquid from the wetter to the dryer end of the channel and help rewetting. Hence, it increases the Critical heat flux (CHF) limit of the system and is almost always favorable.

The Inertia force is expressed as,

$$
F_{i}=\rho \cdot U^{2} \cdot A_{c}
$$

where, $A_{c}$ is the channel cross-sectional area (inertia force acts over channel cross section), $U$ is the fluid mean velocity, $\rho$ is the fluid average density, $\mathrm{kg} / \mathrm{m}^{3}$ and can be expressed as, $\rho=$ $\alpha \cdot \rho_{v}+(1-\alpha) \cdot \rho_{l}$, where $\alpha$ is the void fraction.

Inertia force per unit area,

$$
F_{i}^{\prime \prime}=\rho . U^{2}
$$

Inertia force, $F_{i}$ works at the direction of flow before flow reversal and acts over the channel cross-section. Hence, high $F_{i}$ during flow reversal is not desirable and prevents rewetting as flow direction changes to upstream.

The Shear force is expressed as,

$$
F_{\tau}=\frac{\mu \cdot U \cdot A_{p l}}{D}
$$

where, $\mu$ is the fluid viscosity, (fluid in contact with the channel wall), $U$ is the fluid mean velocity, $A_{p l}$ is the area over which force is acting (shear plane area) and $D$ is the relevant dimension.

Shear force per unit area,

$$
F_{\tau}^{\prime \prime}=\frac{\mu \cdot U \cdot A_{p l}}{D \cdot A_{c}}
$$

Shear force acts against the flow direction and resists motions before flow reversal. However, during flow reversal, it works in downstream direction of the channel and help rewetting. Shear force stabilizes the liquid film flow and promotes homogenous distribution of liquid.

The Buoyancy force is expressed as,

$$
F_{b}=\left(\rho_{v}-\rho_{l}\right) \cdot g \cos \varphi \cdot V
$$

where, $V$ is the volume of bubble, $\varphi$ is the heating surface orientation, $\rho_{v}$ is the vapor density, $\rho_{l}$ is the liquid density, and $g$ is the gravitational acceleration.

Buoyancy force per unit area,

$$
F_{b}^{\prime \prime}=\left(\rho_{v}-\rho_{l}\right) \cdot g \cos \varphi \cdot \frac{V}{A_{c}}
$$


Buoyancy force works according to the channel orientation. In a microchannel, the masses involved are small; however, it may affect the flow due to the large density differences between liquid and vapor phase.

The Evaporation momentum force is expressed as,

$$
F_{M}=\left(\frac{q_{E V}^{\prime \prime}}{h_{l v}}\right)^{2} \cdot \frac{1}{\rho_{v}} \cdot A_{i}
$$

where, $h_{l v}$ is the latent heat of vaporization, $\rho_{v}$ is the vapor density, $q_{E V}$ is the evaporative heat flux at the interface, and $A_{i}$ is the bubble interface area. $q_{E V}^{\prime \prime}$ is assumed equal to the effective heat flux, $q_{\text {eff }}^{\prime \prime}$ in this study.

Evaporation momentum force per unit area,

$$
F_{M}^{\prime \prime}=\left(\frac{q_{E V}^{\prime \prime}}{h_{l v}}\right)^{2} \cdot \frac{1}{\rho_{v}} \cdot \frac{A_{i}}{A_{c}}
$$

Liquid phase changes into to vapor phase during evaporation and increases the velocity of vapor phase. This change of momentum due to velocity change exerts a force at liquid-vapor interface and develops evaporation momentum force. $F_{M}$ always works against the flow direction. Hence, at high heat flux, high $F_{M}$ promotes reverse flows.

In this study, the relative effects of these forces on flow regimes, instabilities and heat transfer performances in flow boiling SiNW microchannels have been identified and validated with literatures.

\section{Experimental study}

Experiments were conducted in a forced convection loop with deionized (DI) water at a mass flux range from $100 \mathrm{~kg} / \mathrm{m}^{2} \mathrm{~s}$ to $600 \mathrm{~kg} / \mathrm{m}^{2} \mathrm{~s}$. Micro devices consist of five parallel straight microchannels and each channel dimension is $\mathrm{W}: 220 \mu \mathrm{m} \times \mathrm{H}: 250 \mu \mathrm{m} \times \mathrm{L}: 10 \mathrm{~mm}$. Both Nanowire and Plainwall micro devices were used to investigate the bubble dynamics during flow boiling in microchannels. The design and fabrication of the microchannel devices were detailed in our previous studies [40]. In this study, two different microchannel configurations with same geometry but different surface conditions were used to investigate the bubble characteristics at liquid-vapor interface. The silicon nanowire surface was thereby produced in smooth silicon surface by electroless electrochemical etching technique with silver nanoparticles (AgNPs) catalyst. These SiNWs were then naturally oxidized to make super hydrophilic surface (approximate contact angle $0^{\circ}$ ) using the Wenzel effect [32, 37]. The Scanning Electron Microscope (SEM) images of SiNW surfaces and Plainwall surfaces are shown in Fig.2. SiNWs are approximately $20 \mathrm{~nm}$ in diameter and $5 \mu \mathrm{m}$ in length and nearly uniformly coated over the heating surface as can be seen from the figure. The experimental apparatus including the test module, flow loop, experimental procedure, and the data reduction method established in our previous studies are adopted in this study. Along with the extensive experimental investigations, high speed visualization at a frame rate 5000fps and theoretical analysis have been performed to reveal the bubble dynamics in flow boiling SiNW microchannels. Force analysis at liquid-vapor interface of vapor bubble has been performed based on flow visualization image analysis and 
theoretical understanding. This force analysis has been used to advance the understanding of unique boiling behaviors in SiNW microchannels.

\section{Results and Discussion}

\subsection{Comparative study between Silicon Nanowire and Plainwall microchannels}

The relative importance of inertia, surface tension, shear, buoyancy, and evaporation momentum forces at liquid-vapor interface of a nucleating bubble in microchannels are studied. Contact angle is a key parameter affecting the wall-bubble (solid-liquid-vapor interface) interactions. Wettability of surface is usually characterized with a contact angle. Its effect on bubble nucleation, departure time, departure diameter, heat transfer performance and CHF was recognized by several investigators [49-51]. The difference between the dynamic contact angle and the static contact angle is small as shown by Kandlikar and Steinke [52], hence the static contact angles are used to calculate surface tension forces. Bubble static contact angles over flat silicon and silicon nanowire are measured and presented in Fig.3. Both SiNW and plain wall microchannel have been considered to calculate force acting on a bubble using simplified equation developed by Kandlikar [48].

(a)
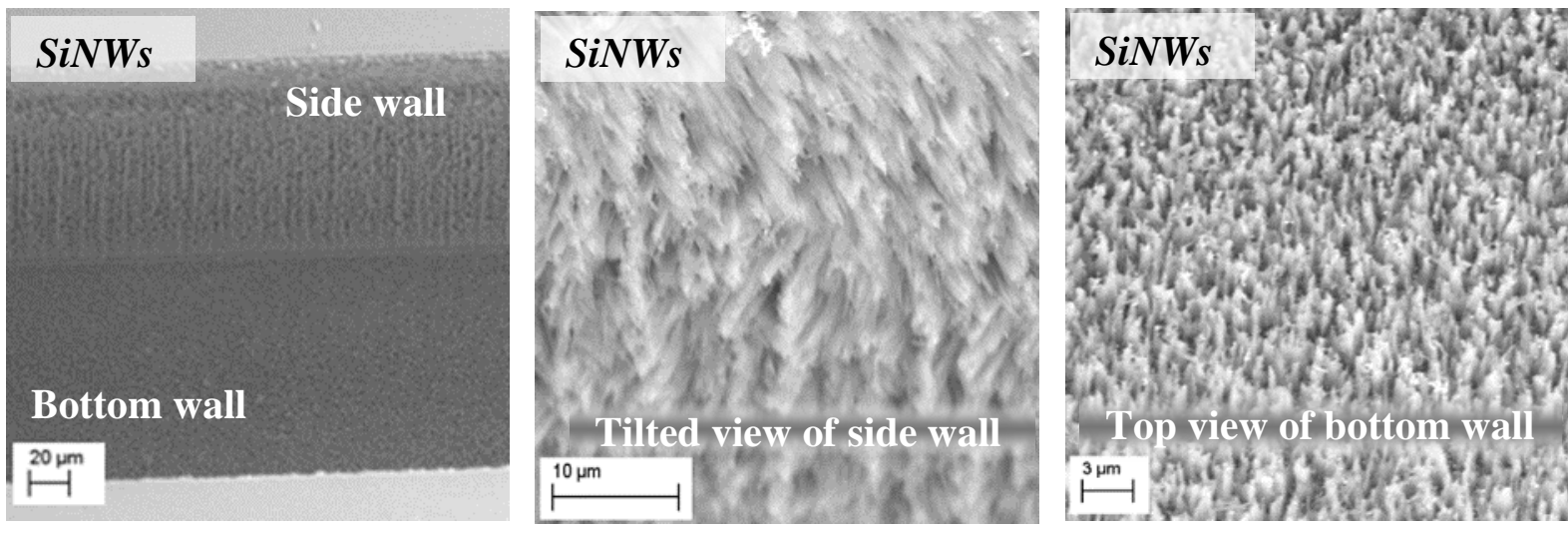

(b)
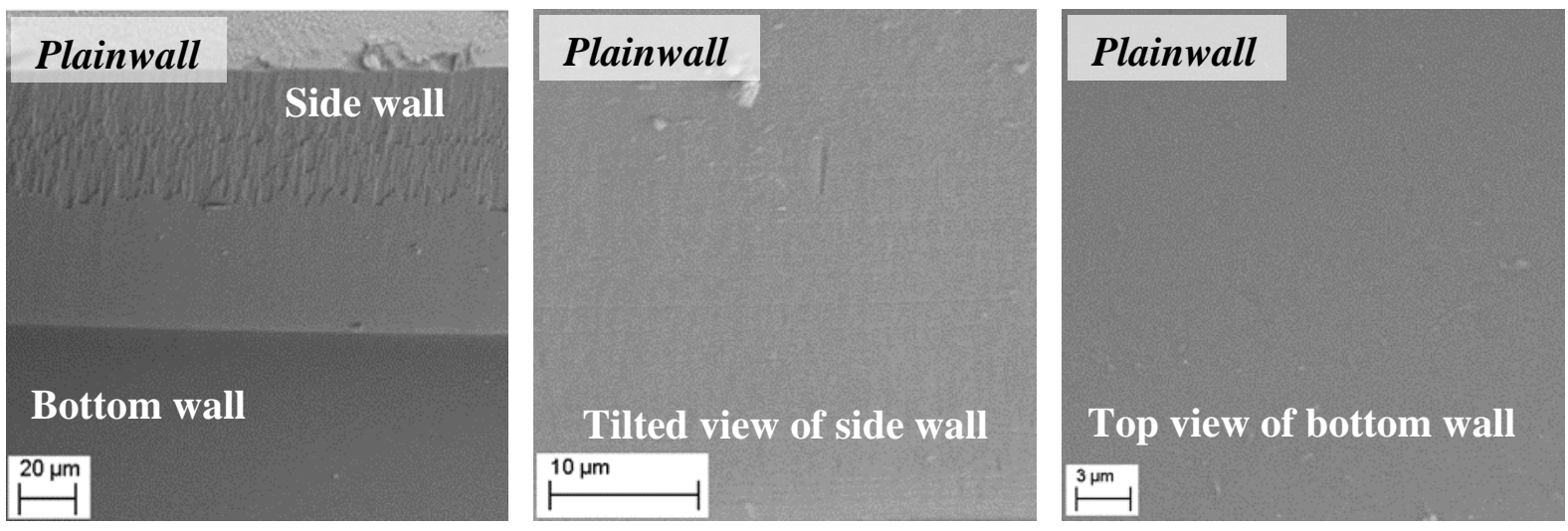

Fig.2. Scanning Electron Microscope (SEM) images of (a) SiNW surfaces, (b) Plainwall surfaces. 
(a)

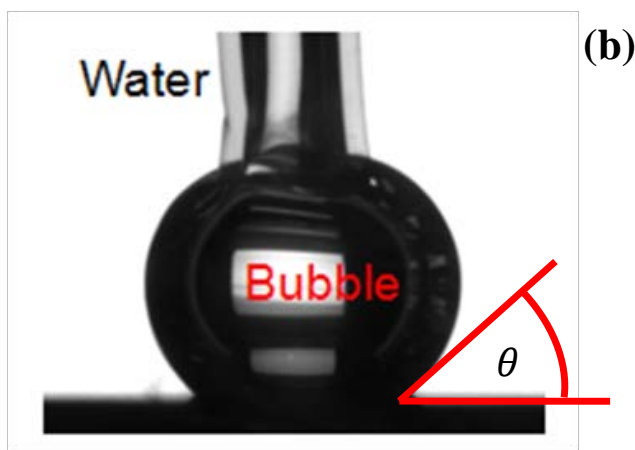

Flat Silicon

Static contact angle

$\left(45.13 \pm 0.67^{\circ}\right)$ (b)

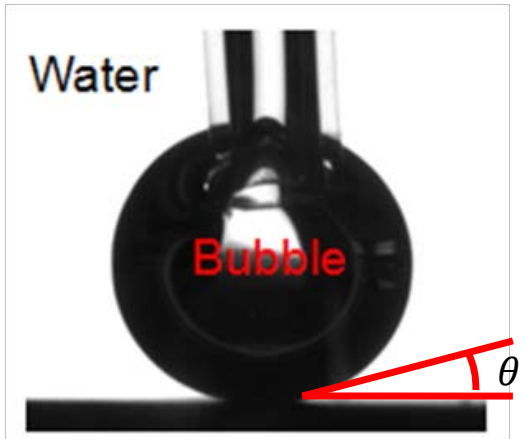

Silicon Nanowire

Static contact angle

$\left(10.21 \pm 2.74^{\circ}\right)$

Fig.3. Static contact angle, $\theta$ for (a) Flat silicon surface and (b) Silicon nanowire surface.

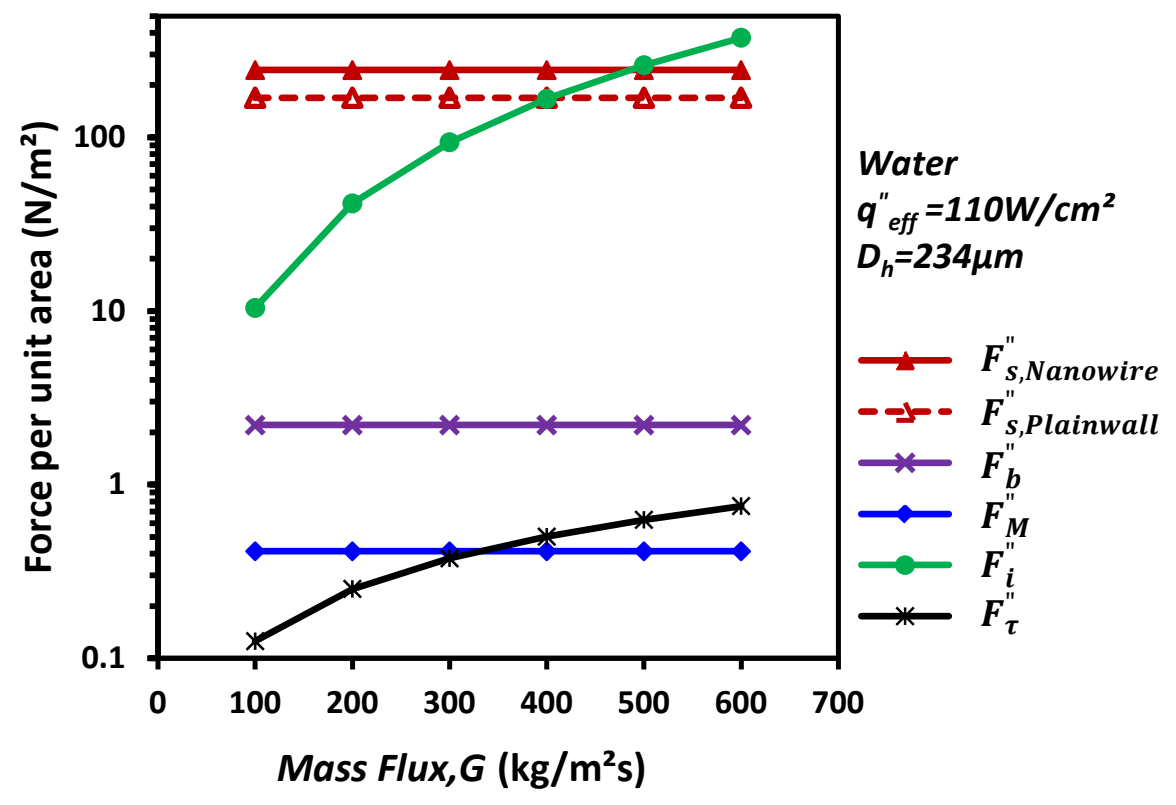

Fig.4. Magnitude of various forces in silicon nanowire and plainwall microchannels.

The comparative results are shown in Fig.4. Forces per unit area have been plotted against mass flux for nanowire microchannels with a hydraulic diameter, $D_{h}=234 \mu \mathrm{m}$ at atmospheric pressure, a heat flux of $110 \mathrm{~W} / \mathrm{cm}^{2}$ and a range of mass fluxes to demonstrate the relative importance of forces in microscale domain. Surface tension force for plainwall microchannels $\left(F_{s, \text { Plainwall }}\right)$ is also plotted for comparison. From Fig.4, shear and evaporation momentum forces have negligible effects in microchannels and effect of shear force increases with the increase of mass flux. Buoyancy force is also small; however, its influence is greater than those of the shear and evaporation momentum forces under the tested conditions. Therefore, it should be considered in analyzing the bubble behavior in flow boiling microchannels. The two most dominant forces in flow boiling microchannels are the inertia force and the surface tension force. Fig. 4 shows that 
inertia force is low in magnitude for small mass flux and increases gradually with the increase of mass flux. At high mass flux, inertia force even overcomes the surface tension force. Surface tension forces for nanowire and plainwall have been calculated based on static contact angle and it can be seen from figure that nanowire has higher magnitude of surface tension than plainwall. Surface tension plays a dominant role in flow boiling heat transfer performances and helps to enhance the system performance and CHF. It can also be seen from figure that above $500 \mathrm{~kg} / \mathrm{m}^{2} \mathrm{~s}$ mass flux, inertia dominates over surface tension force in nanowire microchannel. Inertia force is directed downstream before flow reversal and directed upstream during flow reversal. Hence, high inertia force is unfavorable during flow reversal (prevent rewetting) and induces high system instabilities as illustrated in Fig.5 for nanowire microchannel at $600 \mathrm{~kg} / \mathrm{m}^{2} \mathrm{~s}$.
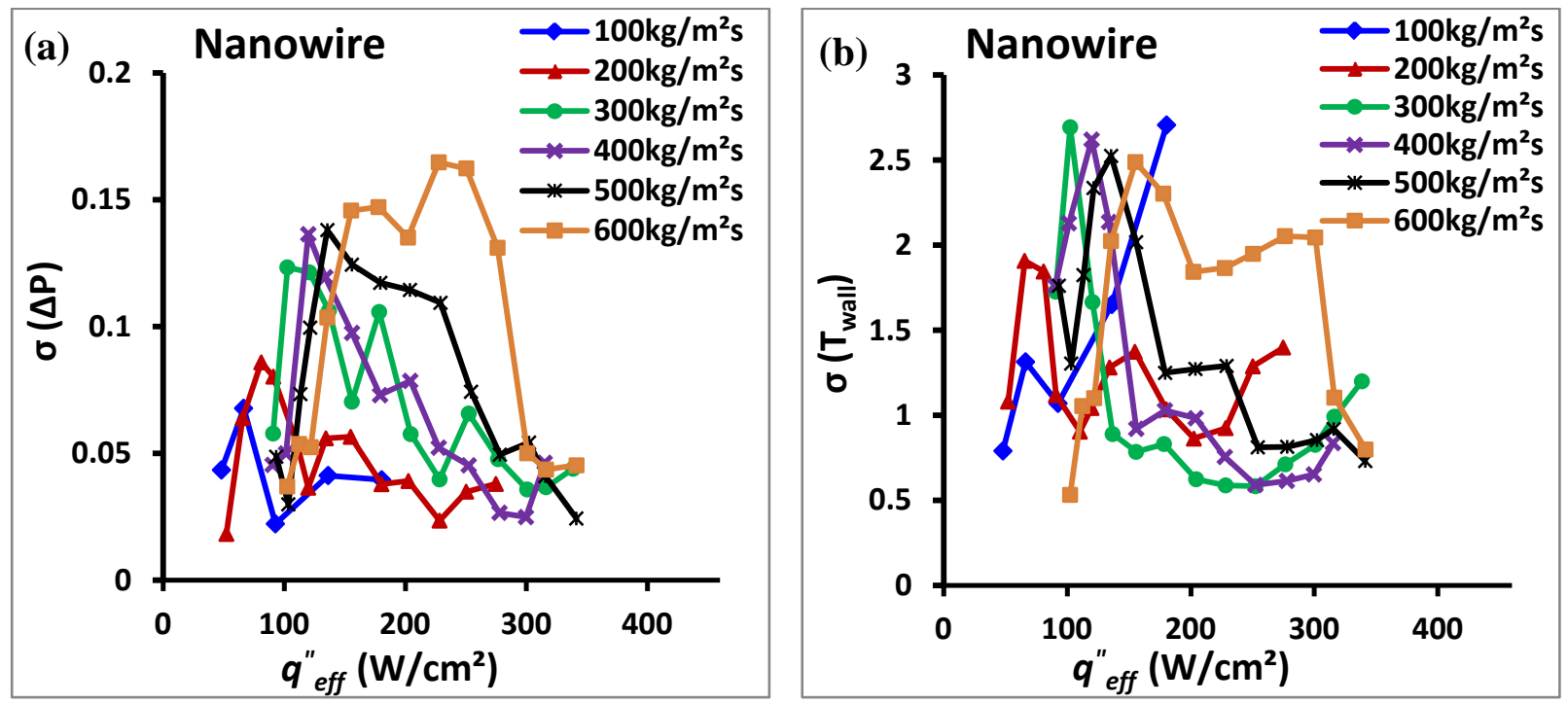

Fig.5. Standard deviation of transient data at various mass fluxes (a) pressure drop instabilities and (b) wall temperature instabilities.

Fig.6 shows the ranges of non-dimensional parameters for flow boiling in SiNW and plainwall microchannels respectively. Capillary number, $\mathrm{Ca}$ is important to flow in microchannels and plotted against Reynolds number, $R e$ (the ratio of inertia to viscous force) as shown in Fig.6a. $C a$ is the ratio of viscous force to surface tension force and it controls the film thickness $(\delta)$ surrounds the vapor bubble. Film thickness significantly depends on Capillary number and increasing the $\mathrm{Ca}$, film thickness also increases. It can be seen from figure that $\mathrm{Ca}$ for plainwall microchannels is higher compare to nanowire microchannels. Therefore, film thickness for plainwall microchannels is also higher than nanowire as can be seen from Fig.7a. Poor heat transfer performances are also observed (shown in Fig.7b) in plainwall due to large film thickness and consequent high thermal resistance. On the other hand, nanowire microchannels maintain thinner film thickness and enhance heat transfer performances. Moreover, unique characteristics of nanowires help continuous rewetting for nanowire microchannels and hence enhance CHF. Weber number, We is the ratio of inertia force to surface tension force and helpful in analyzing bubble nucleation and growth rate. If We is high, bubble removal rate will increase. 
Therefore, bubble growth rate will also decrease and formation of stable annular flow regime will take much longer time. We number is plotted against $R e$ in Fig.6b. It can be seen from the figure that We number for plainwall microchannels is higher than nanowire microchannels. Hence, bubble growth takes longer time and bubble growth cycle duration is much higher in plainwall microchannels compare to nanowire microchannels as validated in Fig.8 in our visualization study. Bond number, Bo is the ratio of buoyancy force to surface tension force and $B o$ is plotted as a function of $R e$ as shown in Fig.6c. It can be seen from the figure that Bo is higher for plainwall microchannels compare to nanowire; therefore nanowire is more gravity insensitive and suitable for practical applications. Boiling number, $B l$ represents the ratio of heat flux with mass flux and latent heat. $B l$ number is plotted against $R e$ in Fig.6d and it can be seen from the figure that $B l$ decreases with $R e$ for both the nanowire and plainwall microchannels.

(a)

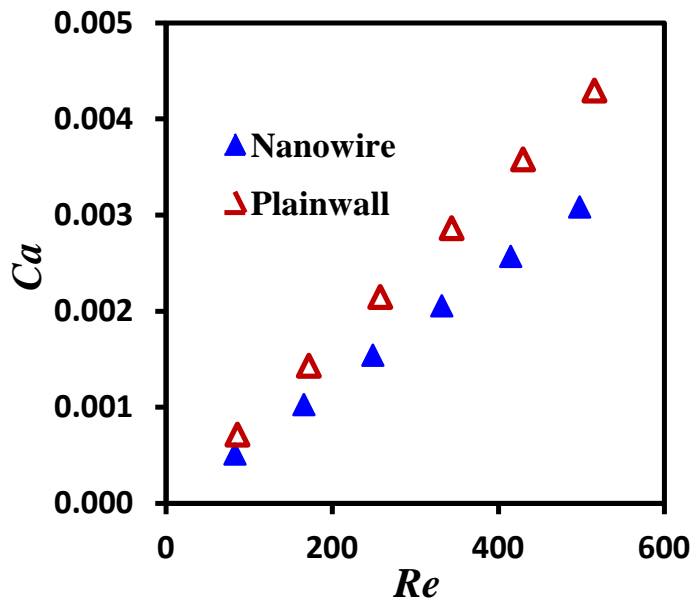

(c)

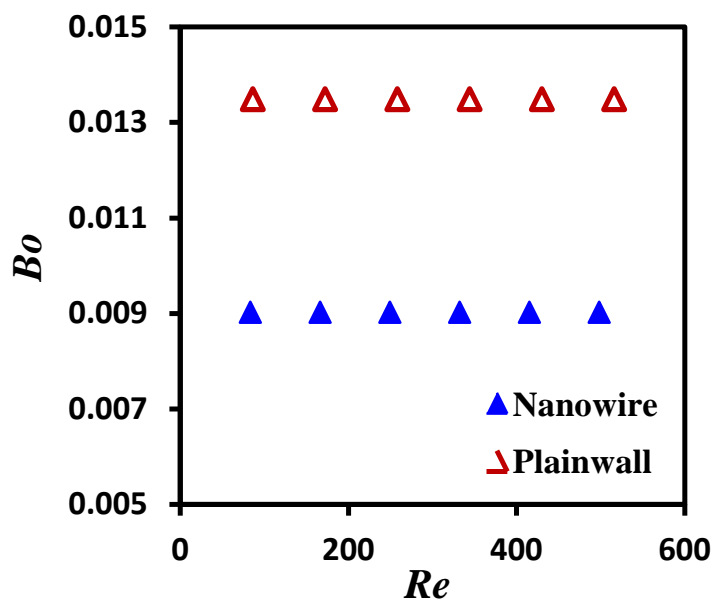

(b)

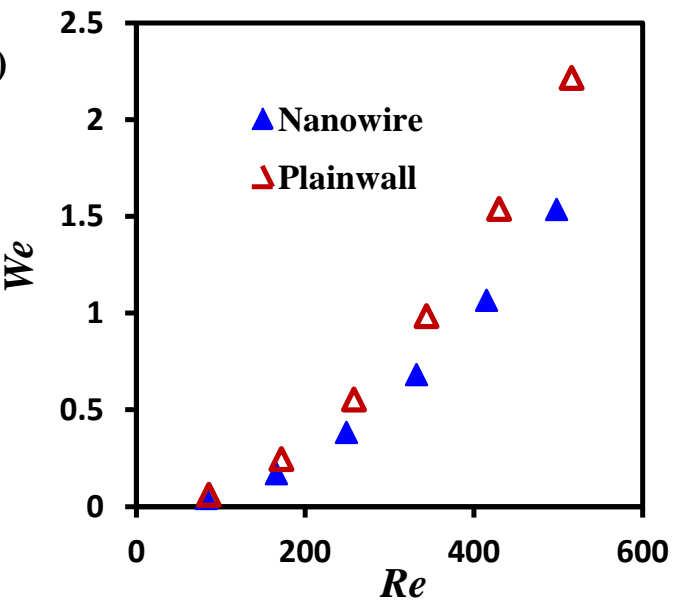

(d)

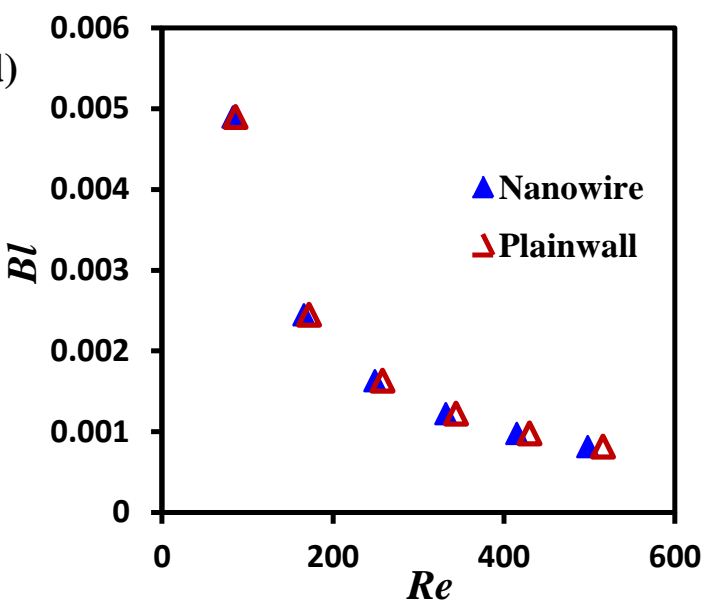

Fig.6. Comparison of Non-dimensional Numbers between nanowire and plainwall microchannels. 

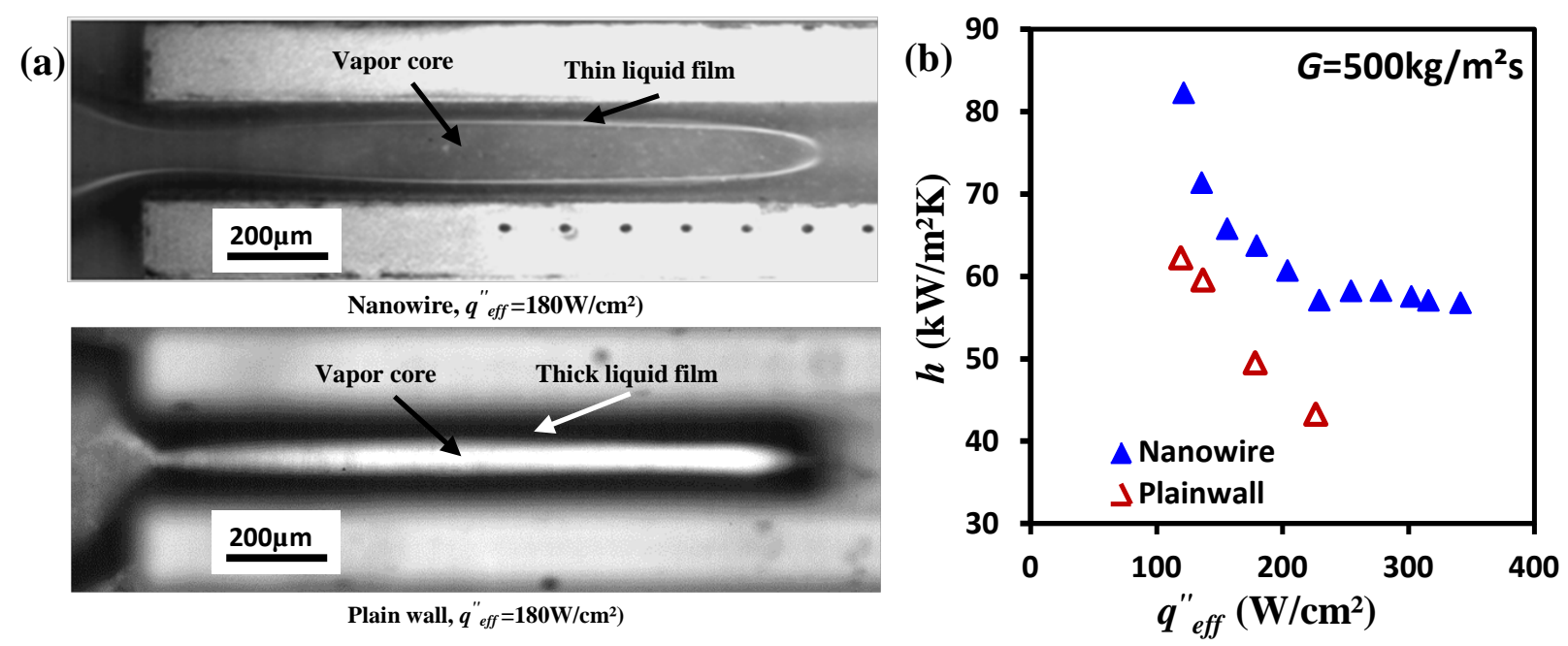

Fig.7. Comparison between silicon nanowire and plainwall microchannels.

(a)

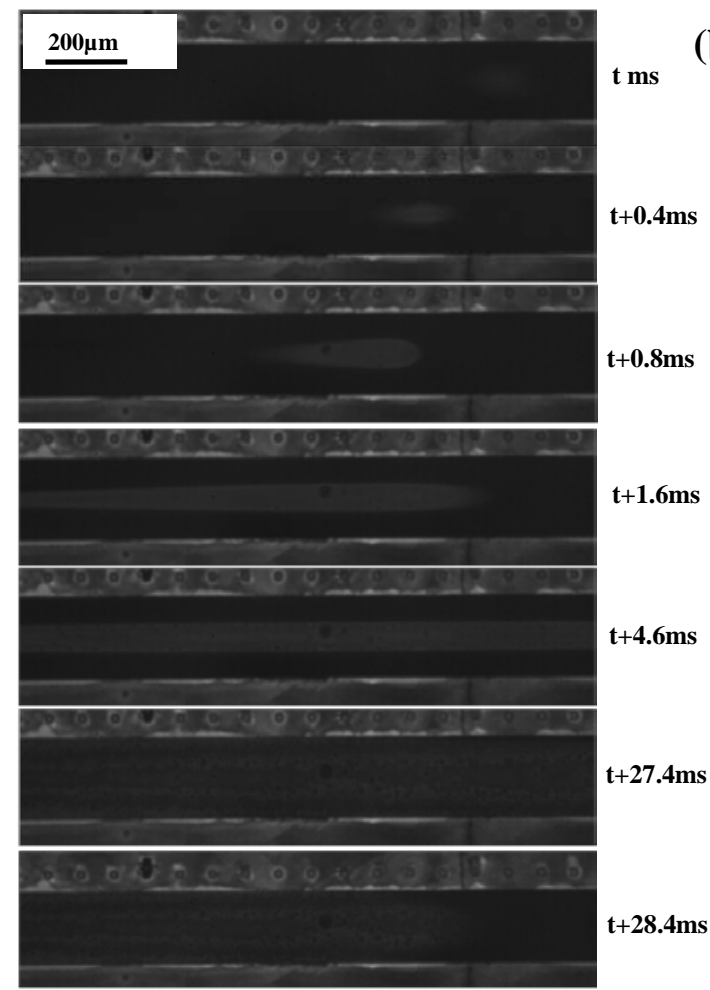

(b)

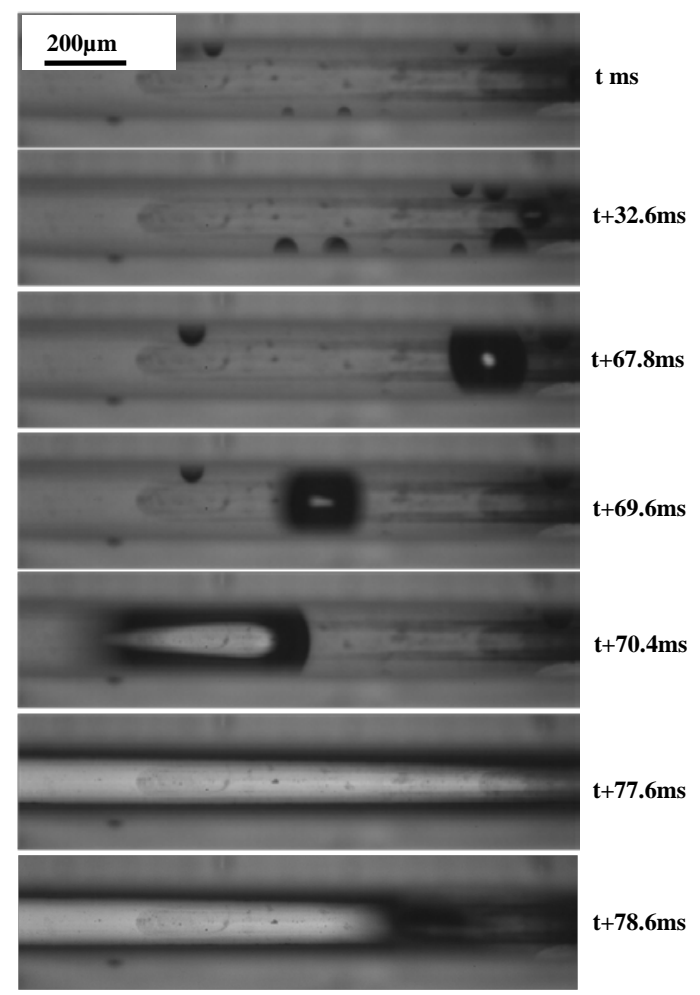

Fig 8. Sequential images at $G=200 \mathrm{~kg} / \mathrm{m}^{2} \mathrm{~s}$ and $q_{\text {eff }}^{\prime \prime}=110 \mathrm{~W} / \mathrm{cm}^{2}$ (a) Nanowire and (b) Plainwall.

\subsection{Effect of various parameters on forces acting on liquid-vapor interface and consequent heat transfer performances:}

In this section, results from our force analysis have been validated with published literatures. New criteria based on the forces acting on liquid-vapor interface to predict and understand the flow boiling mechanism in microscale domain are proposed. Several methods, i.e., flow regime map based on experimental and visualization studies, empirical and semi-empirical heat transfer 
correlations etc. have been proposed to predict flow boiling heat transfer performances in microchannels [53-55]. However, none of these methods can fully explain the complex flow boiling behaviors in microchannels and the differences in behaviors differ from case to case. The reason behind this differences of heat transfer performance from case to case lies on forces acting on liquid-vapor interface. Forces acting on liquid-vapor interface play an important role in establishing flow regime and consequently, determining heat transfer performances. In microchannel flow boiling, forces acting on liquid-vapor interface are affected by various parameters: wettability (contact angle), channel dimension, mass flux, heat flux etc. The role of these parameters on forces acting on liquid-vapor interface and consequent heat transfer performances are identified and validated in this section based on experimental results and prominent published literatures.

\subsubsection{Effect of contact angle:}

Contact angle has a significant effect on flow boiling heat transfer performances as it influences the wettability of the surface. Effects of contact angle on various forces acting on the liquidvapor interface and heat transfer performances in flow boiling microchannels are plotted in Fig.9. Forces are calculated for SiNW microchannels (contact angle, $\theta \approx 10^{\circ}$ ) and plainwall microchannels (contact angle, $\theta \approx 45^{\circ}$ ). As shown in Fig.9a that surface tension force decreases with the increase of contact angle at the same operating condition and therefore, the wettability of surface decreases with contact angle. The heat transfer coefficient (HTC) is plotted against heat flux for both the microchannels in Fig.9b and it can be seen from the figure that the surface with lower contact angle (highly wetted) shows better performance. Similar characteristics have been reported in the literature as shown in Fig.10 by Phan et al. [50]. Forces have been calculated for different static contact angles which have been reported by Phan et al. [56] for different surface structures. Force analysis in Fig.10a shows that the surface tension force decreases with the increase of contact angle and therefore, heat transfer performances deteriorates from $\mathrm{Ti}$ surface (contact angle, $\theta \approx 49^{\circ}$ ) to diamond-like carbon (DLC) surface (contact angle, $\theta \approx 63^{\circ}$ ) as shown in Fig.10b. From the above discussion, it can be concluded that surface tension force plays a significant role in governing heat transfer performances in microchannel flow boiling and increasing surface tension force in a system can enhance heat transfer. High surface tension force enhances the surface rewetting properties, increases bubble departure diameter, decrease bubble departure frequency and maintain uniform thin film along the liquid-vapor interface, thus, enhance heat transfer performance and Critical heat flux (CHF) of the flow boiling microchannel systems. 
(a)

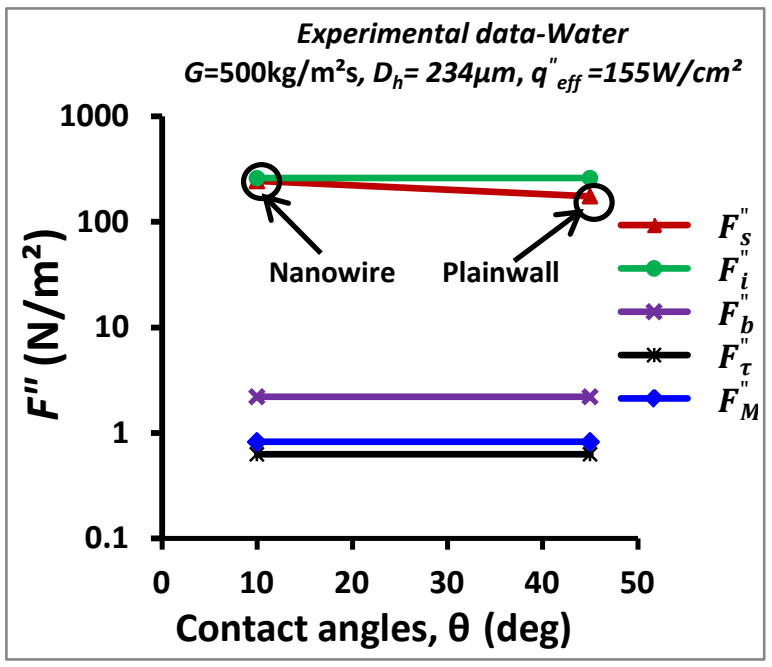

(b)

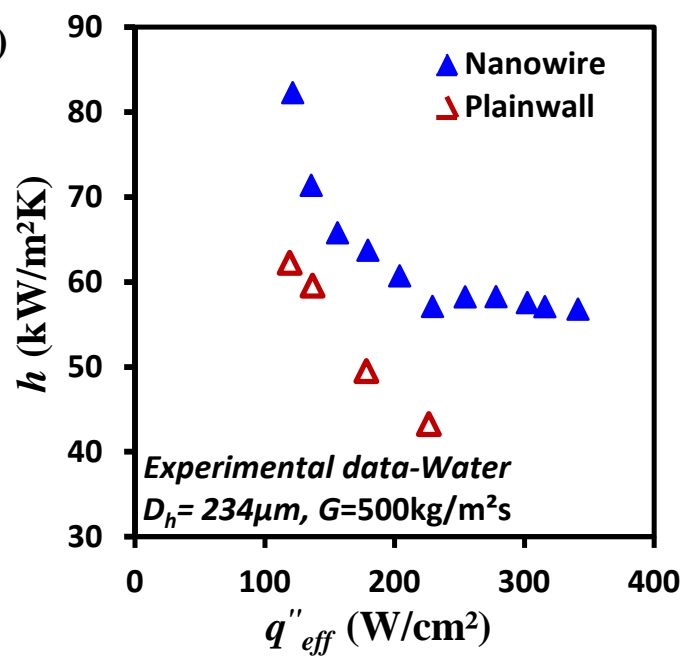

Fig.9. Effect of contact angle on (a) various forces in microchannels, and (b) heat transfer coefficient.

(a)

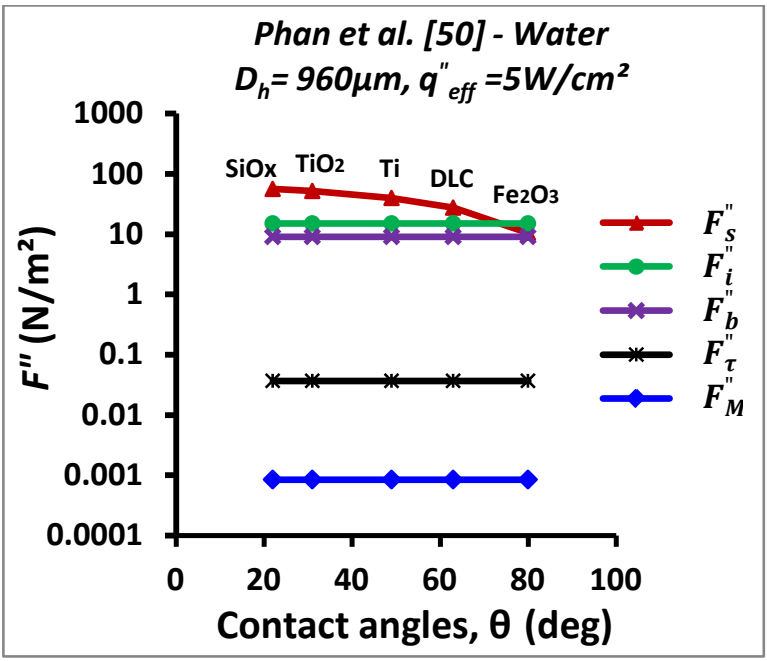

(b)

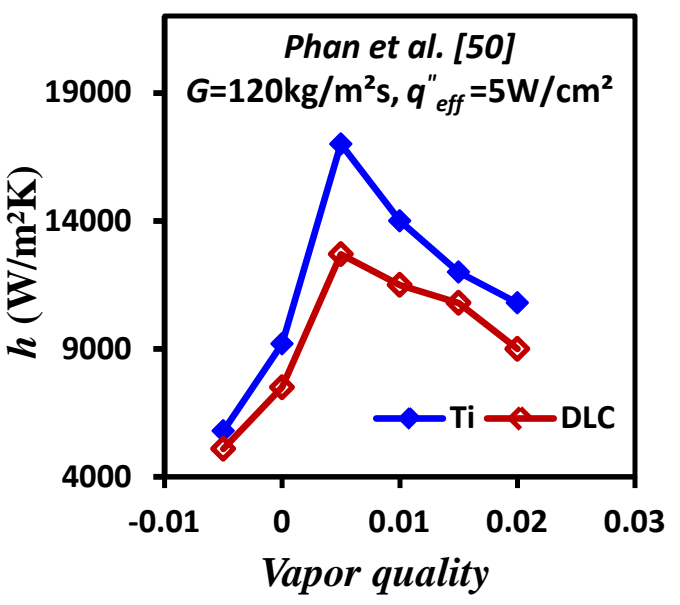

Fig.10. Effect of contact angle on (a) various forces in microchannel, and (b) heat transfer coefficient.

\subsubsection{Effect of Dimension:}

Microchannel dimension has a significant effect on flow boiling heat transfer performances due to the transition of flow regimes; and forces acting on the liquid-vapor interface influence the flow regime development. Therefore, influences of microchannel dimension on forces acting on the liquid-vapor interface are necessary to understand the physical phenomena underlying the observed behaviors. Effects of channel dimension on forces and consequent heat transfer performances have been plotted in Fig.11 and 12. Channel properties and heat transfer data have been adopted from Holcomb et al. [57] and Alam et al. [58]. It can be seen from the Fig.11a and 12a that the surface tension and shear force decrease and buoyancy force increases with the increase of channel hydraulic diameter. In addition, heat transfer performances deteriorate with 
the increase of channel dimension as shown in Fig.11b. An interesting heat transfer coefficient curve against channel hydraulic diameter has been reported by Alam et al. [58] as shown in Fig.12b. It can be seen from the figure that heat transfer coefficients increase with channel dimension increase and then decrease gradually with the increment of channel dimension and then remain insensitive to channel dimension. Alam et al. [58] reported that annular flow was the dominant flow regime in the smallest channel and early partial dryout occurred due to very thin film thickness. Whereas, increasing channel dimension, flow regime shifted from annular to slug flow regime for medium channel dimension ranges and slug to bubbly regime for large channel dimension ranges as reported. Similar phenomena have been also reported by other researchers $[10,59]$. A better prediction and explanation of these results can be achieved by force analysis at the liquid vapor interface as shown in Fig.12a. It can be seen from the figure that surface tension dominates over other forces for small channel dimension $\left(D_{h} \approx 160,200 \mu \mathrm{m}\right)$ and HTC increases with the increase of channel diameter due to delay of partial dryout. Once the inertia force dominates over surface tension force with hydraulic diameter exceeding $D_{h} \approx 400 \mu \mathrm{m}$, HTC starts to decrease due to the shift of flow regime. Furthermore, with the increase of buoyancy force, HTC becomes insensitive to channel dimension due to the nucleate boiling dominance and quick removal of nucleating bubble from surface. Thus, force analysis can play an important role in predicting heat transfer performance in flow boiling microchannels and optimized system design.

(a)

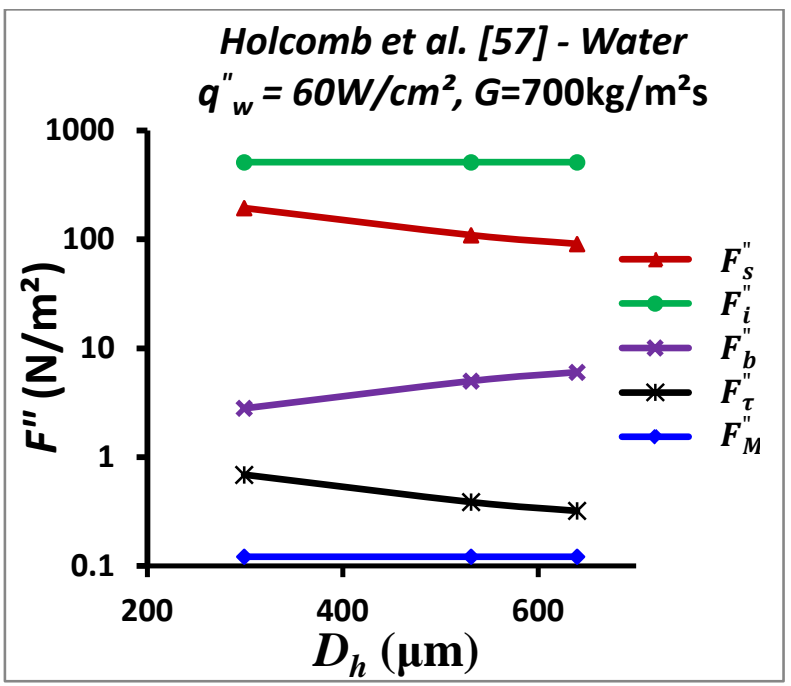

(b)

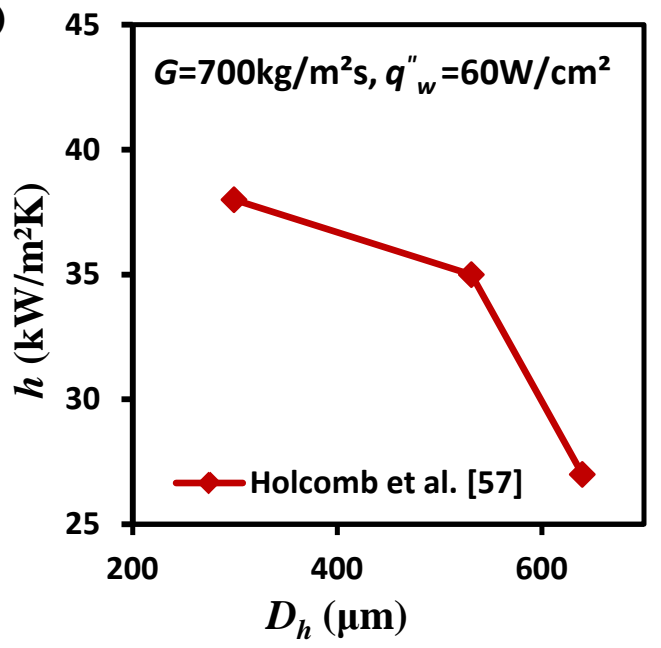

Fig.11. Effect of channel dimension on (a) various forces in microchannels, and (b) heat transfer coefficient. 
(a)

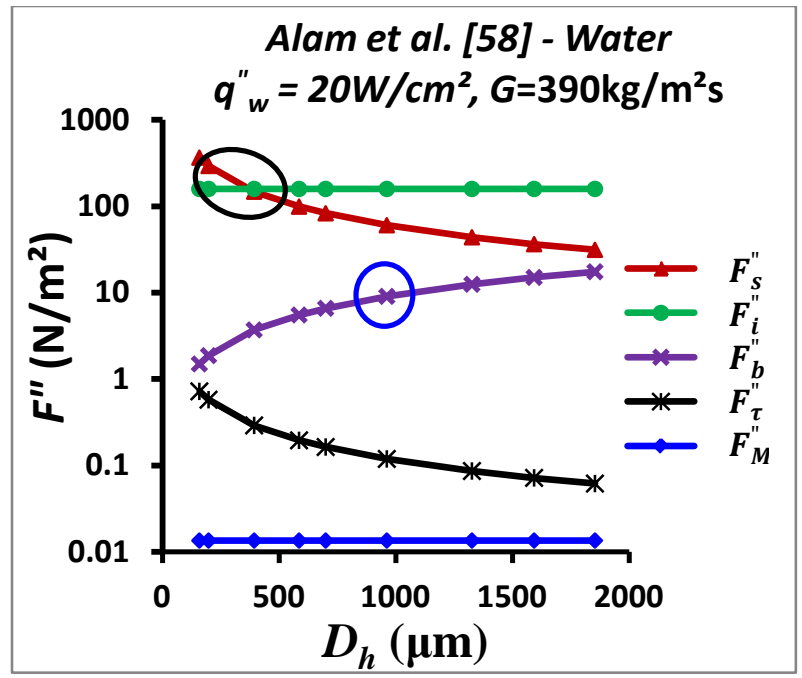

(b)

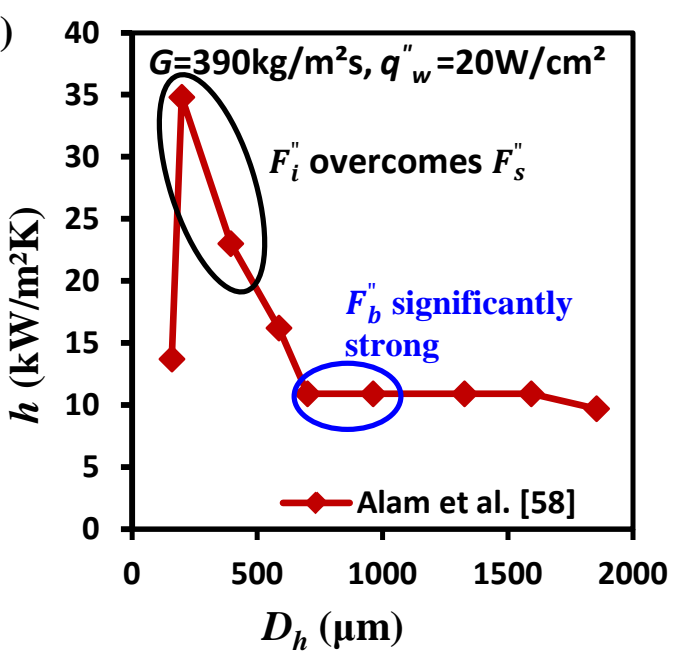

Fig.12. Effect of channel dimension on (a) various forces in microchannels, and (b) heat transfer coefficient.

\subsubsection{Effect of Heat flux:}

Effects of heat flux on forces acting on liquid-vapor interface and consequent heat transfer coefficient have been investigated and the findings are plotted in Fig.13. Though the magnitudes of evaporation momentum force, $F_{M}$ and shear force, $F_{\tau}$ are very small compare to inertia and surface tension force, a significant effect and influence of evaporation momentum and shear force has been observed over flow boiling heat transfer performances in microchannels. It can be seen from Fig.13a that evaporation momentum force increases with the increasing heat flux and gradually exceeds shear force and buoyancy force at different mass fluxes. Furthermore, HTC is observed to decrease with the increase of heat flux as shown in Fig.13b. Evaporation momentum force is caused due to the change in momentum of working fluid as phase change takes places. $F_{M}$ always works against the flow direction. Hence, high $F_{M}$ promotes reverse flow and channel blockage (reduce channel rewetting) at high heat flux. Therefore, local dryout approaches and reduces HTC. Similar phenomena have been observed in the literatures as shown in Fig.14. Forces have been calculated and HTCs have been plotted for the data adopted from Holcomb et al. [57], Kosar et al. [28] and Alam et al. [58]. An increasing HTC with the increasing heat flux has been observed from Fig.14 at low heat flux ranges when shear force dominates over evaporation momentum force. Since, shear force stabilizes the liquid thin film flow and promotes homogenous distribution of liquid; therefore, it may help promoting HTC. However, similar to our experimental data, once evaporation momentum force dominates over shear force at high heat flux ranges, HTC curves become insensitive or show decreasing trend with the increasing heat flux may be due to instabilities and local dryout caused by high flow reversal, channel blockage and lack of rewetting. 
(a)

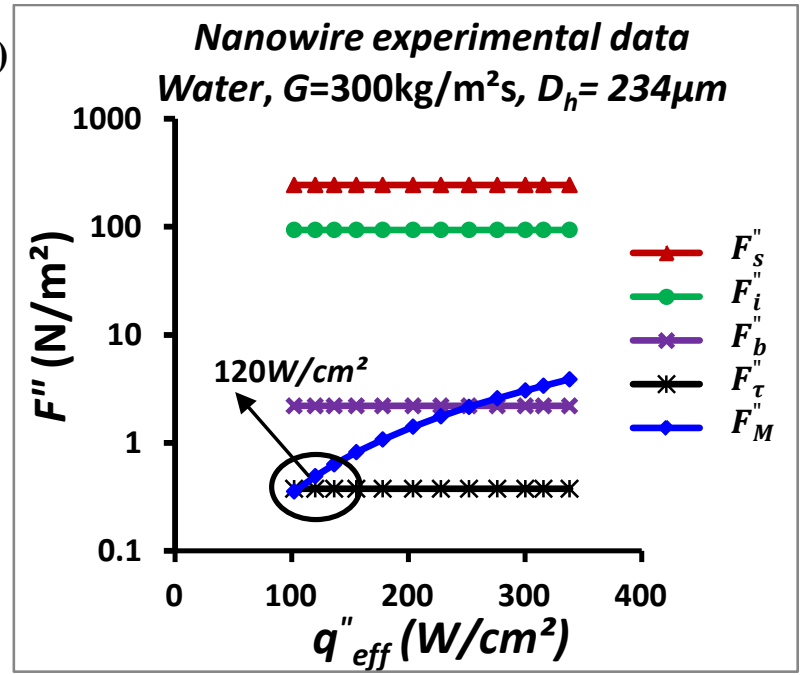

(b)

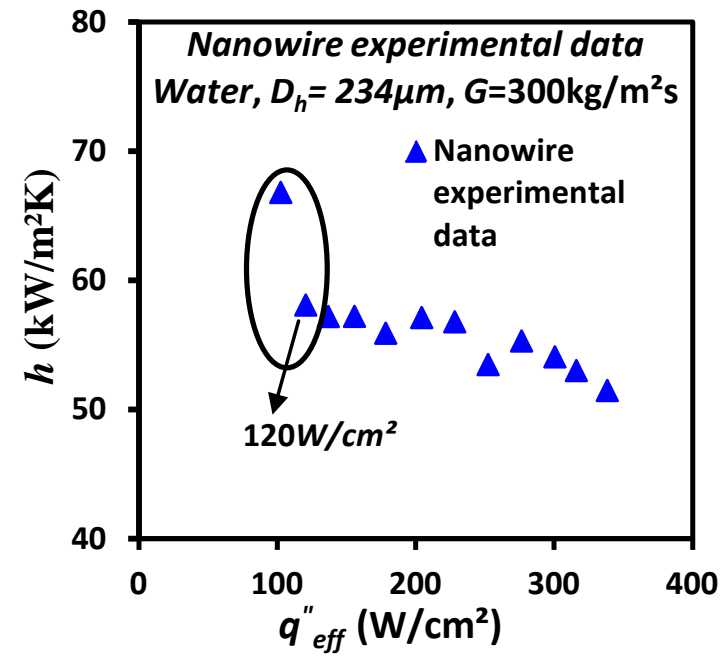

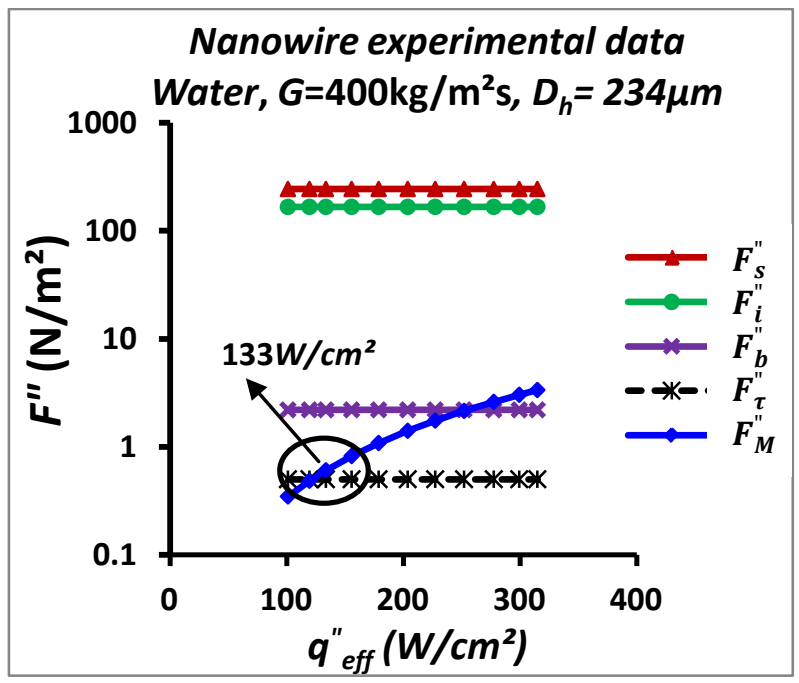

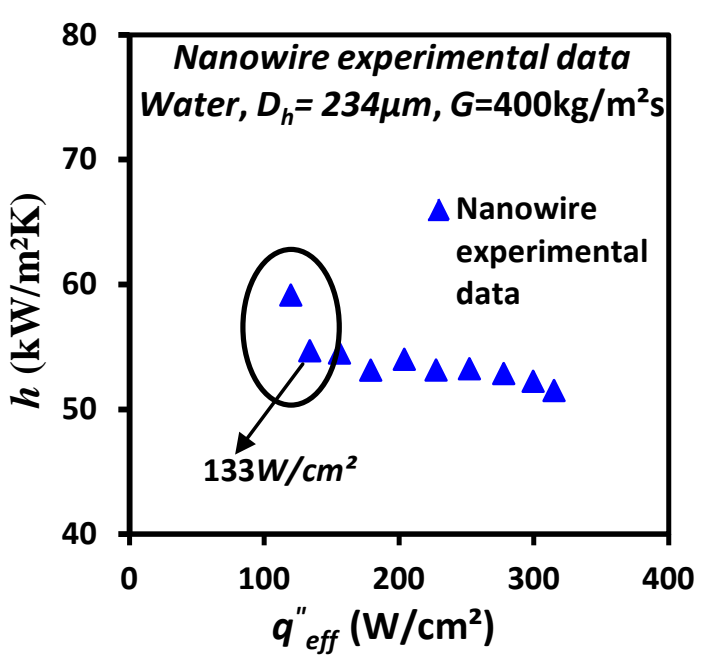

Fig.13. Effect of Heat flux on (a) various forces in microchannels, and (b) heat transfer coefficient.

(a)
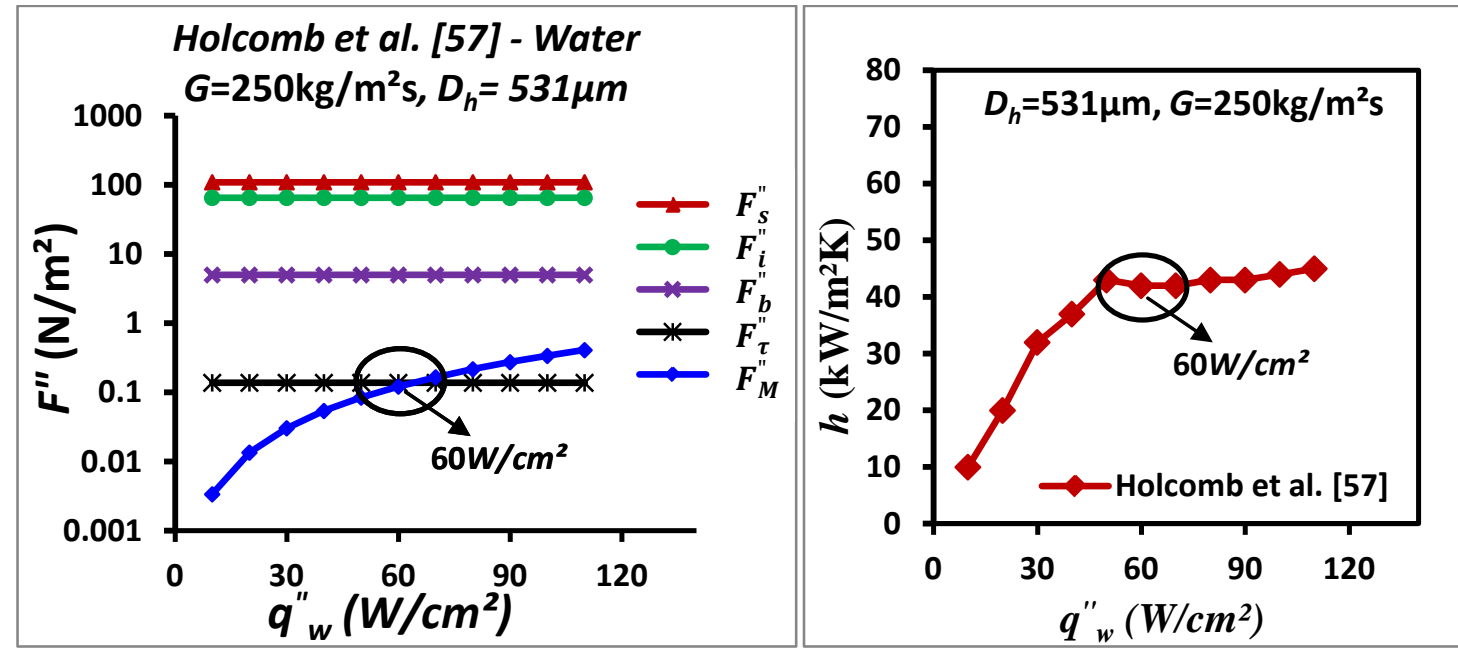
(b)
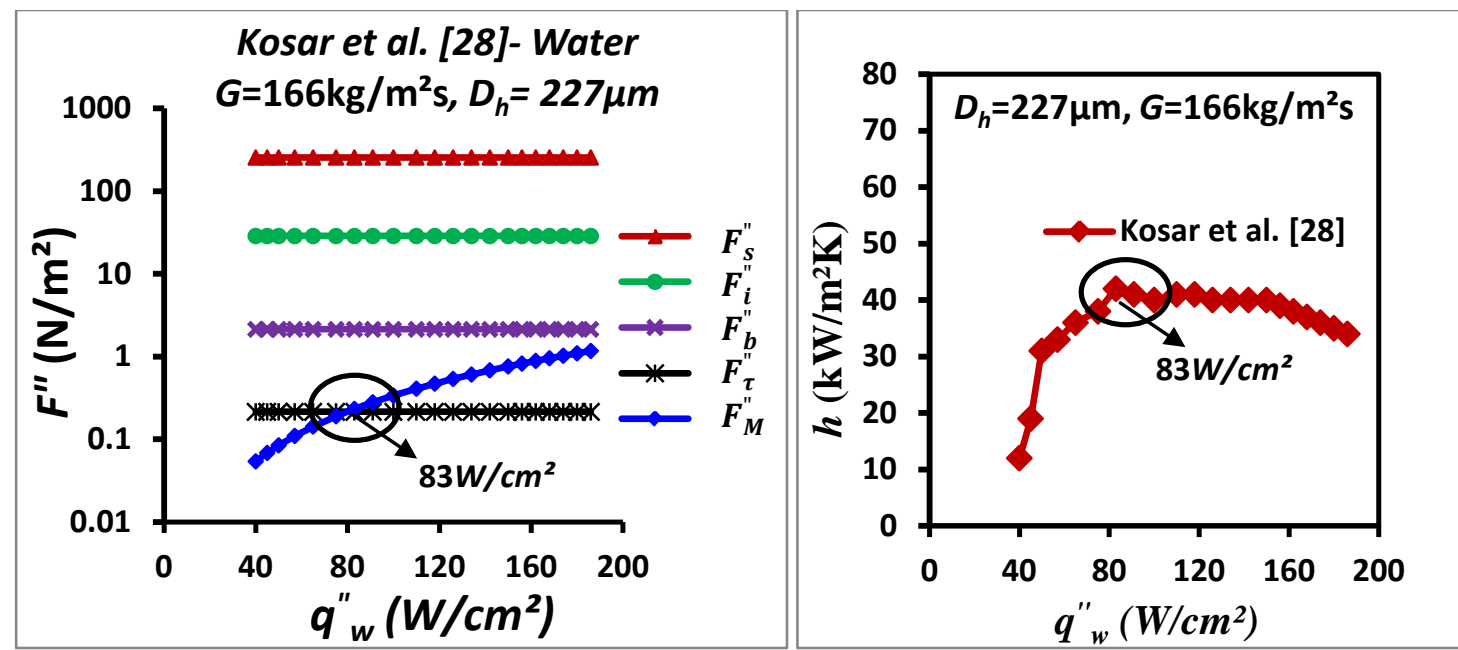

(c)
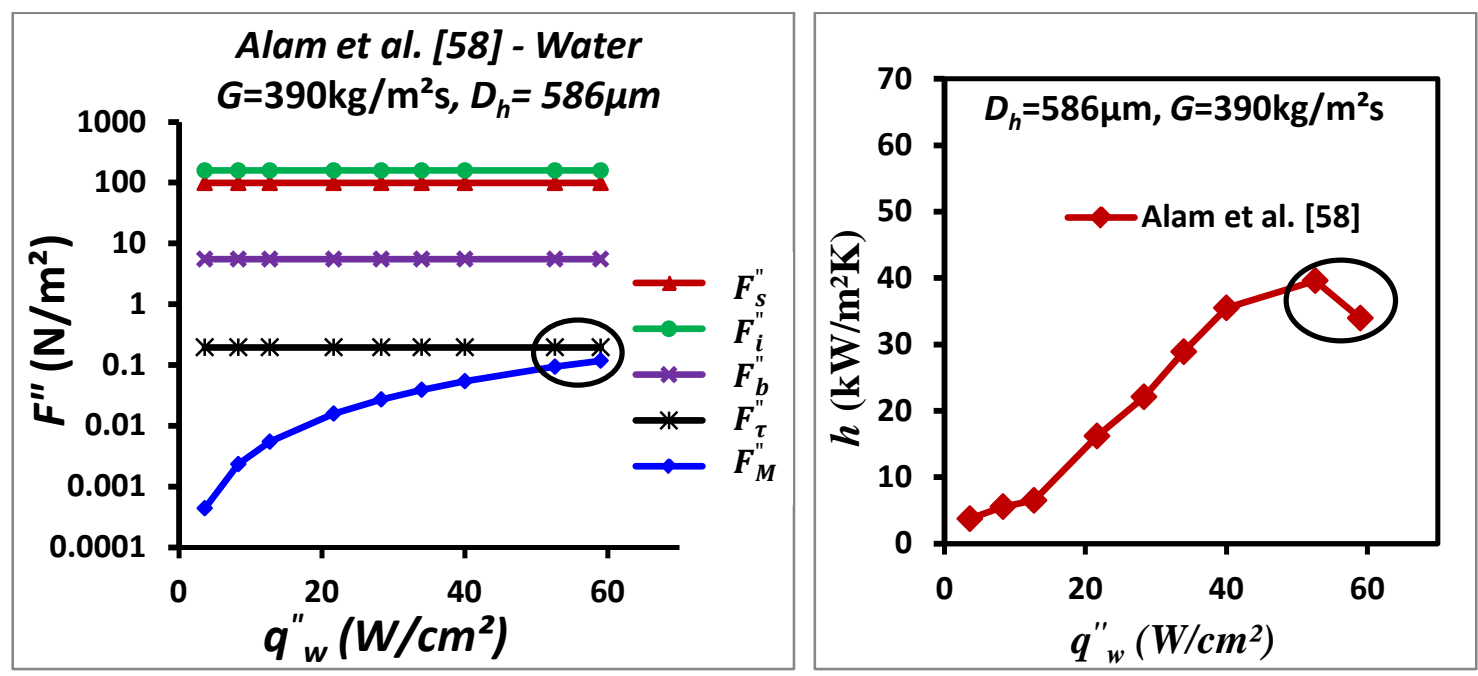

Fig.14. Effect of Heat flux on various forces and heat transfer coefficient in microchannels (a) Holcomb et al. [57], (b) Kosar et al. [28], and (c) Alam et al. [58] .

\subsubsection{Effect of Mass flux:}

Effects of mass flux on the forces acting on liquid-vapor interface and the consequent HTC for flow boiling nanowire microchannels have been plotted in Fig.15. A significant effect of mass flux on inertia and shear force has been observed and these forces increase as the mass flux increases as shown in Fig.15a. Surface tension force dominates over inertia force at low mass flux, however, inertia force exceeds surface tension force in flow boiling nanowire microchannels at high mass flux. As illustrated in Fig.15b, as the mass flux increases, HTC also increases from low to medium range of mass flux; whereas, HTC curve shows insensitivity or decreasing trend with the further increase of mass flux. Similar trends have been observed as plotted in Fig.16 for the data adopted from Holcomb et al. [57] and Kosar et al. [28]. It can be seen from Fig. 16a that HTC decreases with the increasing mass flux if inertia force dominates over surface tension force. Flow regime shifts from annular (thin film evaporation) to nucleate boiling regime at strong inertia and weak surface tension force due to quick bubble removal 
process and small bubble departure diameter and thus deteriorates HTC. Whereas, HTC increases with the increasing mass flux if surface tension force dominates over inertia forces as can be seen in Fig. 16b. Flow boiling instabilities and local dryout may appear at strong surface tension and very weak inertia force due to decreased bubble departure frequency and increased bubble departure diameter. Increasing mass flux at this condition helps confined bubble removal process, delays local dryout and reduces flow reversal, and thus helps to improve HTC. Therefore, prediction of heat transfer performances can be achieved for different mass flux by force analysis and inertia and surface tension force can be used as the transition criteria of flow boiling behavior in microchannels. Similar trend is also observed for data presented by Steinke and Kandlikar [60] and Bertsch et al. [61] as shown in Fig.17 and 18.
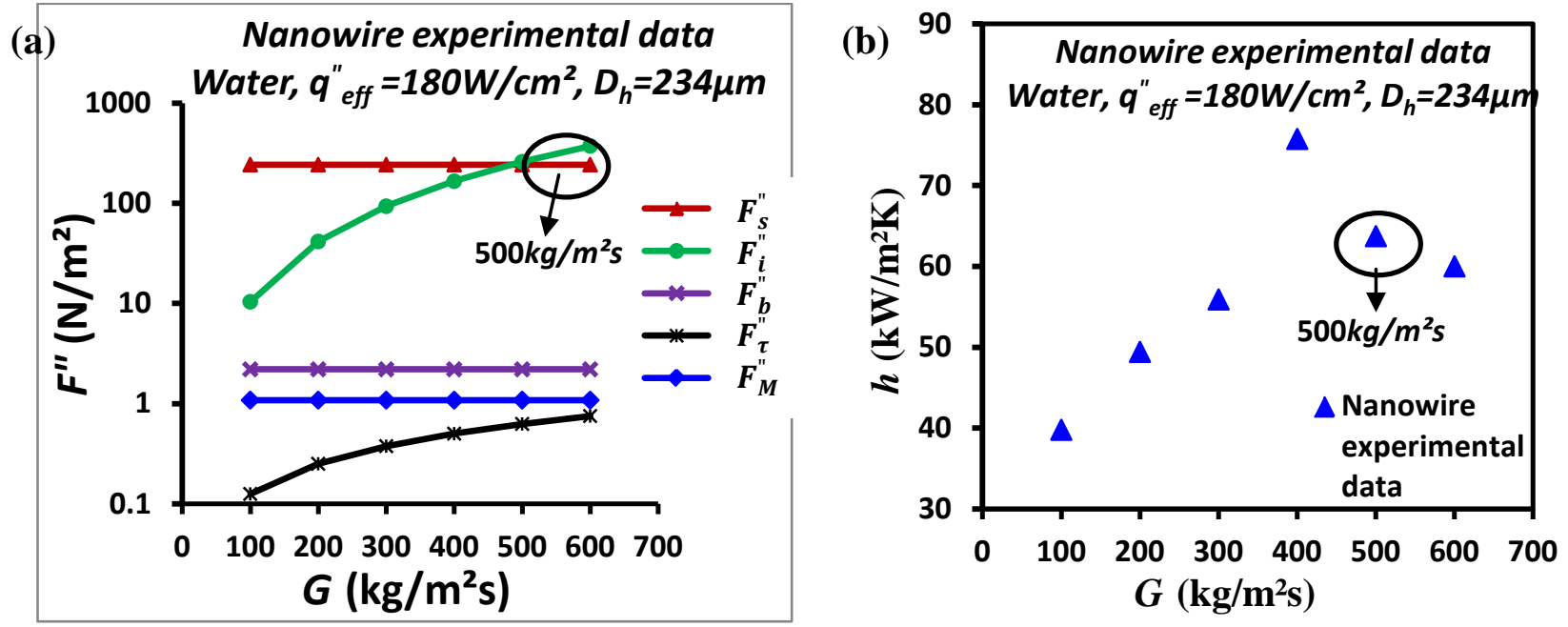

Fig.15. Effect of Mass flux on (a) various forces in microchannel, and (b) heat transfer coefficient.

(a)

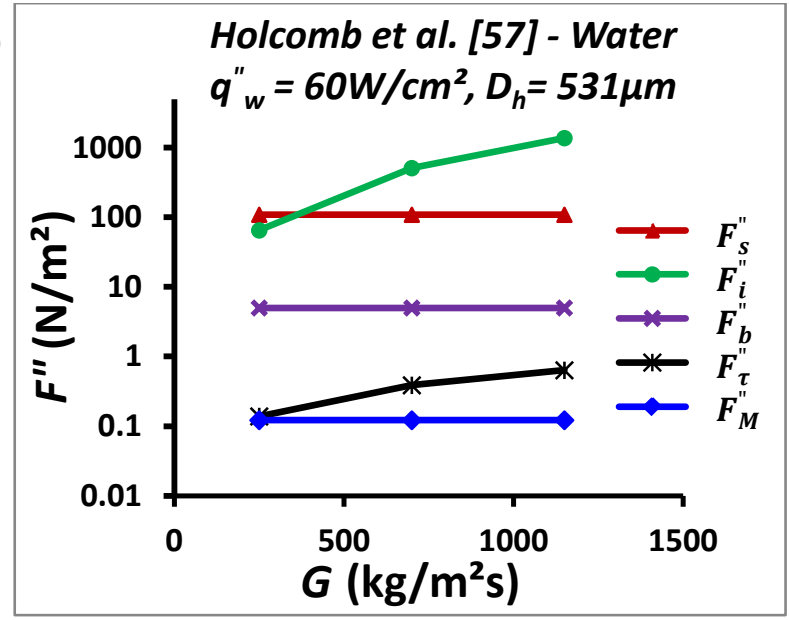

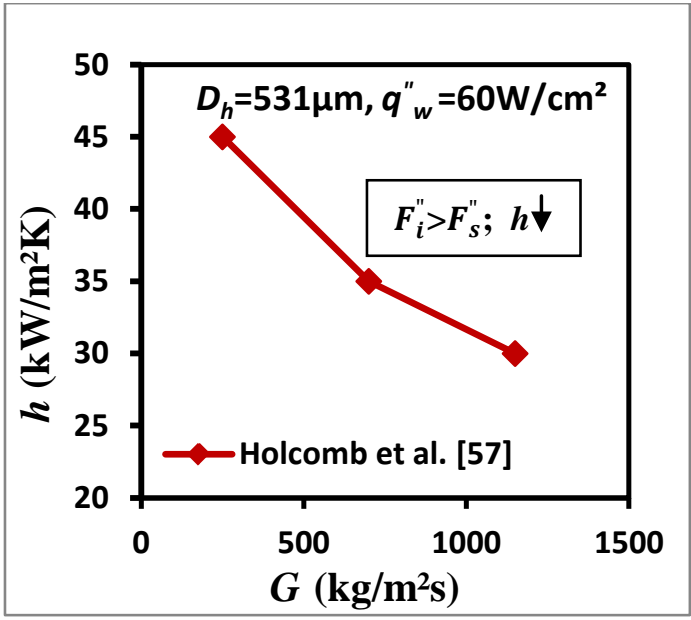


(b)

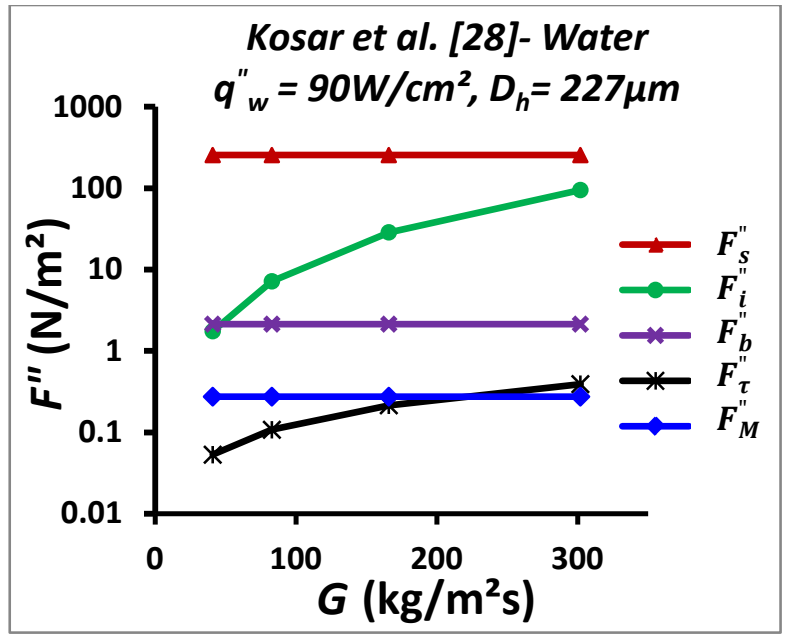

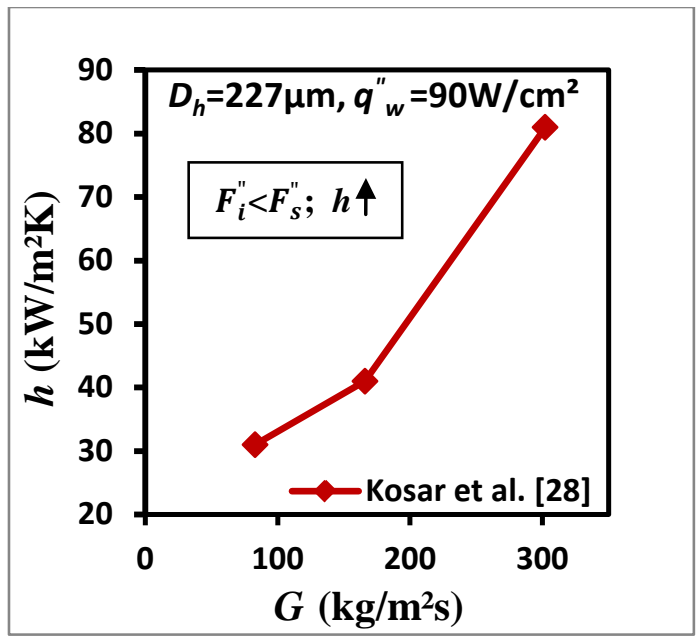

Fig.16. Effect of Mass flux on various forces and heat transfer coefficient in microchannels (a) Holcomb et al. [57], and (b) Kosar et al. [28].

(a)

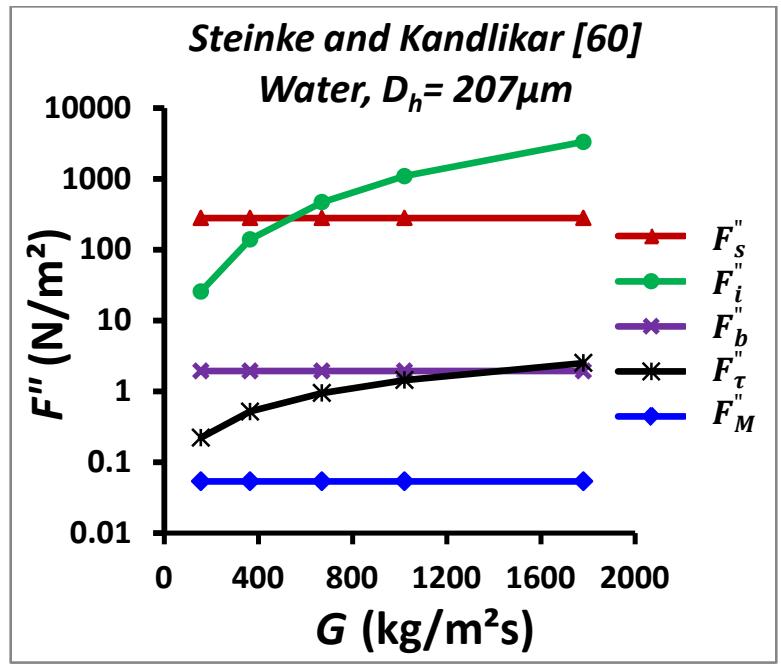

(b)

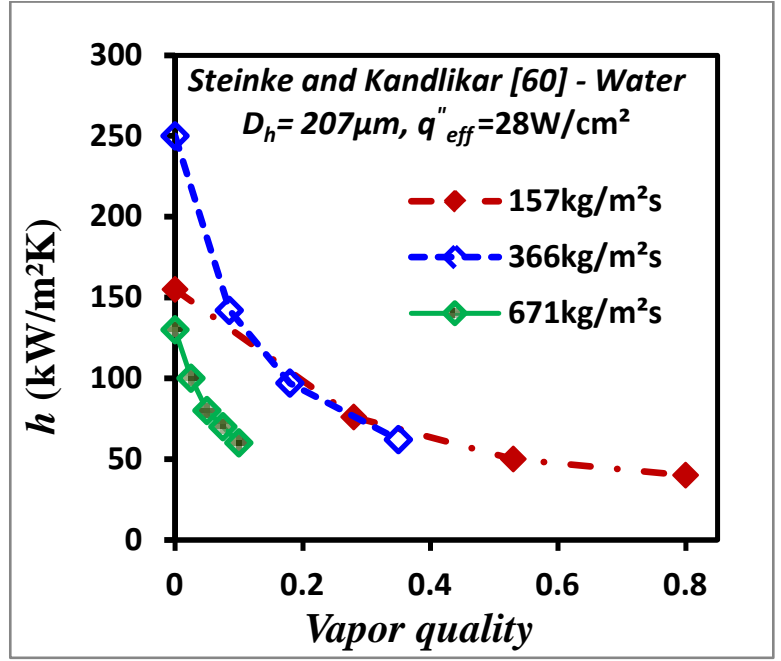




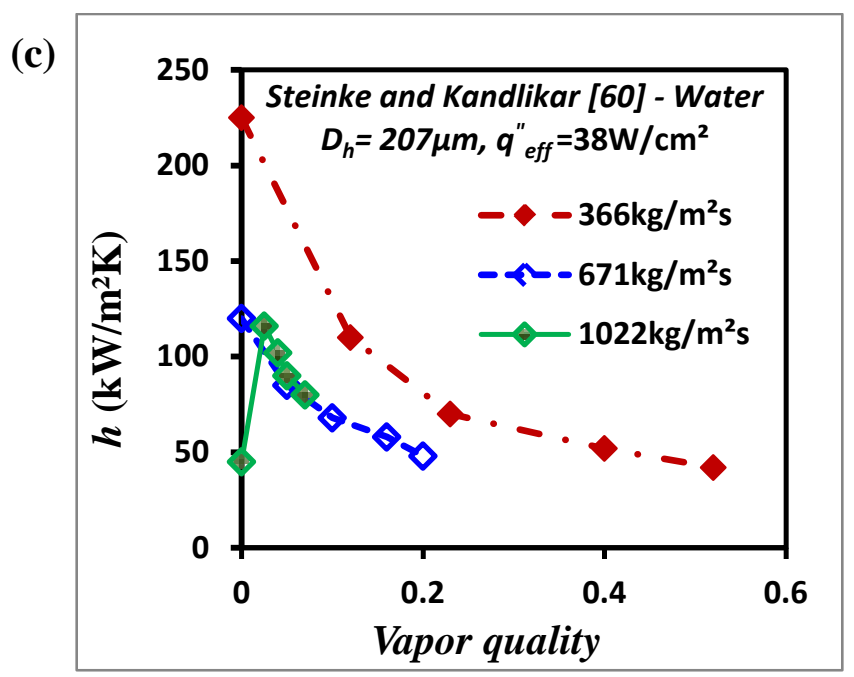

Fig.17. Effect of Mass flux on various forces and heat transfer coefficients in microchannels as observed in Steinke and Kandlikar [60].

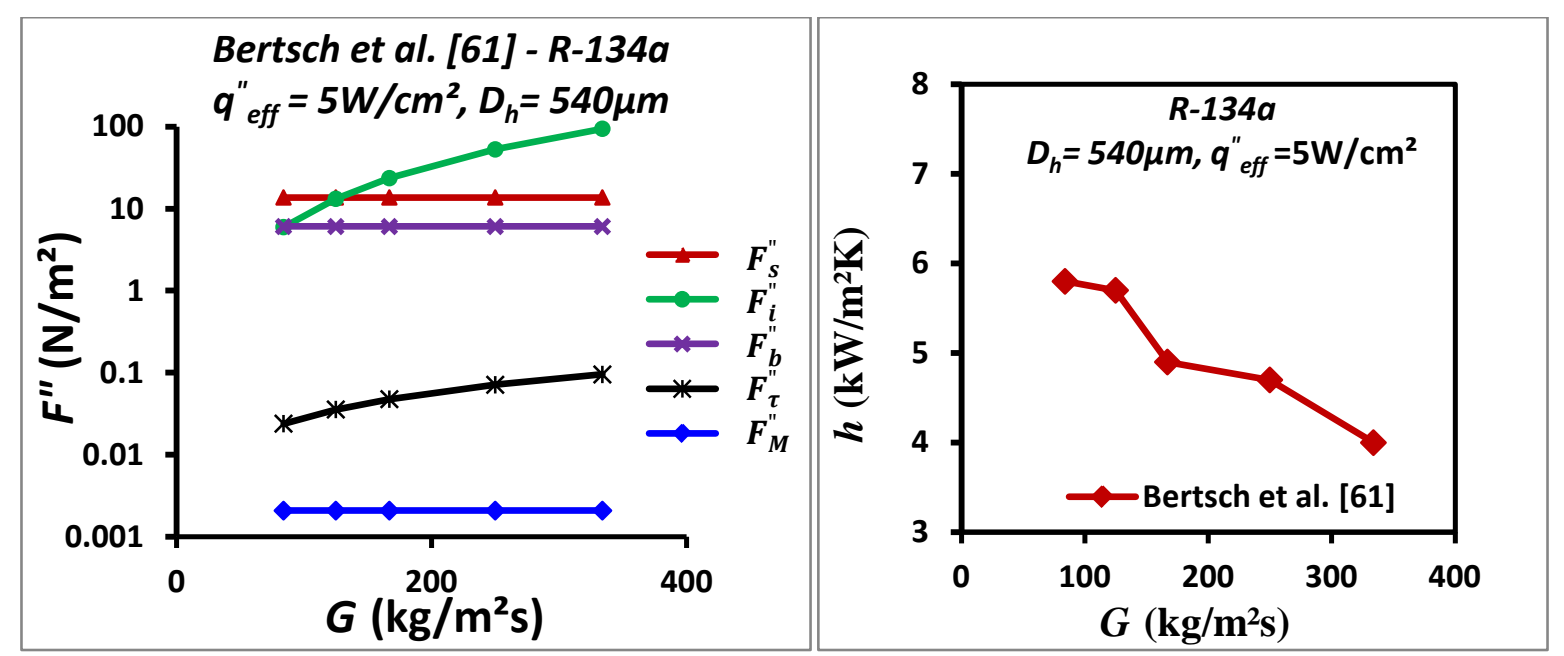

Fig.18. Effect of Mass flux on various forces and heat transfer coefficients in microchannels as observed in Bertsch et al. [61].

\section{Conclusion}

The relative effects of different forces on flow regimes, instabilities and heat transfer performances of flow boiling in Silicon Nanowire microchannels and plainwall microchannels have been identified. Surface tension force is observed to be dominant in flow boiling microchannels at low to moderate mass fluxes and inertia force dominates at higher mass fluxes. In addition, enhanced surface rewetting and CHF in nanowire microchannels are owing to higher surface tension force at liquid-vapor interface and capillary dominance. Whereas, low Weber number in SiNW helps maintaining uniform and stable thin film and improves heat transfer performances. Moreover, results from these studies are compared with literatures and excellent agreements have been observed. Thus, prediction of heat transfer performances in flow boiling microchannels can be achieved under different operating conditions, channel geometries and 
surface properties by force analysis and range of inertia, surface tension, shear, buoyancy and evaporation momentum forces can be used as the transition criteria of flow boiling behavior in microchannels.

\section{Acknowledgements}

This work was supported by NASA under Award No NNX14AN07A. SEM figures in this study were taken in the Electron Microscopy Center at University of South Carolina. Part of the microfabrication was performed at the Cornell Nanoscale Facility (CNF), a member of the National Nanotechnology Infrastructure Network of United States, which is supported by the National Science Foundation under the Grant ECS-0335765.

\section{References}

[1] B. Agostini, M. Fabbri, J.E. Park, L. Wojtan, J.R. Thome, B. Michel, State of the Art of High Heat Flux Cooling Technologies, Heat Transfer Engineering, 28(4) (2007) 258-281.

[2] A. Royne, C.J. Dey, D.R. Mills, Cooling of photovoltaic cells under concentrated illumination: a critical review, Solar Energy Materials and Solar Cells, 86(4) (2005) 451-483.

[3] L. Xiaobing, L. Sheng, A Microjet Array Cooling System for Thermal Management of High-Brightness LEDs, Advanced Packaging, IEEE Transactions on, 30(3) (2007) 475-484.

[4] K.F. Jensen, Microreaction engineering - is small better?, Chemical Engineering Science, 56(2) (2001) 293-303.

[5] J. Kobayashi, Y. Mori, K. Okamoto, R. Akiyama, M. Ueno, T. Kitamori, S. Kobayashi, A Microfluidic Device for Conducting Gas-Liquid-Solid Hydrogenation Reactions, Science, 304(5675) (2004) 1305-1308.

[6] Multiphase flow in lab on chip devices: A real tool for the future?, Lab on a Chip, 8(7) (2008) 10101014.

[7] R.L. Hartman, K.F. Jensen, Microchemical systems for continuous-flow synthesis, Lab Chip, 9(17) (2009) 2495-2507.

[8] G. Hetsroni, D. Klein, A. Mosyak, Z. Segal, E. Pogrebnyak, Convective boiling in parallel microchannels, in: ASME 2003 1st International Conference on Microchannels and Minichannels, American Society of Mechanical Engineers, 2003, pp. 59-67.

[9] S.V. Garimella, C. Sobhan, Transport in microchannels-a critical review, Annual review of heat transfer, 13(13) (2003).

[10] T. Harirchian, S.V. Garimella, Microchannel size effects on local flow boiling heat transfer to a dielectric fluid, International Journal of Heat and Mass Transfer, 51(15) (2008) 3724-3735.

[11] S.G. Kandlikar, M. Steinke, S. Tian, L.A. Campbell, High-speed photographic observation of flow boiling of water in parallel mini-channels, in: 35th Proceedings of National Heat Transfer Conference, 2001.

[12] S.G. Kandlikar, P. Balasubramanian, An Experimental Study on the Effect of Gravitational Orientation on Flow Boiling of Water in $1054 \times 197 \mathrm{~m}$ Parallel Minichan nels, Journal of Heat Transfer, 127(8) (2005) 820-829.

[13] Y. Peles, Two-phase boiling flow in microchannels-instabilities issues and flow regime mapping, ASME Paper No. ICMM2003-1069, (2003).

[14] C.-J. Kuo, Y. Peles, Pressure effects on flow boiling instabilities in parallel microchannels, International Journal of Heat and Mass Transfer, 52(1) (2009) 271-280.

[15] H. Wang, R.B. Peterson, Enhanced boiling heat transfer in parallel microchannels with diffusion brazed wire mesh, Components and Packaging Technologies, IEEE Transactions on, 33(4) (2010) 784793. 
[16] H.Z. Cao, H.B. Xu, N. Liang, C.Q. Tian, Experiment investigation of R134a flow boiling process in microchannel with cavitation structure, Heat Transfer Engineering, 32(7-8) (2011) 542-553.

[17] H. Kubo, H. Takamatsu, H. Honda, Effects of size and number density of micro-reentrant cavities on boiling heat transfer from a silicon chip immersed in degassed and gas-dissolved FC-72, Journal of Enhanced Heat Transfer, 6(2-4) (1999).

[18] K.J. Geisler, A. Bar-Cohen, Confinement effects on nucleate boiling and critical heat flux in buoyancy-driven microchannels, International Journal of Heat and Mass Transfer, 52(11) (2009) 24272436.

[19] B.J. Jones, S.V. Garimella, Surface roughness effects on flow boiling in microchannels, Journal of Thermal Science and Engineering Applications, 1(4) (2009) 041007.

[20] L. Zhang, E.N. Wang, K.E. Goodson, T.W. Kenny, Phase change phenomena in silicon microchannels, International journal of heat and mass transfer, 48(8) (2005) 1572-1582.

[21] C.-J. Kuo, Y. Peles, Local measurement of flow boiling in structured surface microchannels, International journal of heat and mass transfer, 50(23) (2007) 4513-4526.

[22] T.J. Hendricks, S. Krishnan, C. Choi, C.-h. Chang, B. Paul, Enhancement of pool-boiling heat transfer using nanostructured surfaces on aluminum and copper, International Journal of Heat and Mass Transfer, 53(15) (2010) 3357-3365.

[23] A. Morshed, F. Yang, M.Y. Ali, J.A. Khan, C. Li, Enhanced flow boiling in a microchannel with integration of nanowires, Applied Thermal Engineering, 32 (2012) 68-75.

[24] H.T. Phan, N. Caney, P. Marty, S. Colasson, Flow boiling of water on nanocoated surfaces in a microchannel, Journal of Heat Transfer, 134(2) (2012) 020901.

[25] N. Singh, V. Sathyamurthy, W. Peterson, J. Arendt, D. Banerjee, Flow boiling enhancement on a horizontal heater using carbon nanotube coatings, International Journal of Heat and Fluid Flow, 31(2) (2010) 201-207.

[26] D. Li, G. Wu, W. Wang, Y. Wang, D. Liu, D. Zhang, Y. Chen, G. Peterson, R. Yang, Enhancing flow boiling heat transfer in microchannels for thermal management with monolithically-integrated silicon nanowires, Nano letters, 12(7) (2012) 3385-3390.

[27] J. Chang, S. You, Boiling heat transfer phenomena from microporous and porous surfaces in saturated FC-72, International Journal of Heat and Mass Transfer, 40(18) (1997) 4437-4447.

[28] A. Koşar, C.-J. Kuo, Y. Peles, Boiling heat transfer in rectangular microchannels with reentrant cavities, International Journal of Heat and Mass Transfer, 48(23) (2005) 4867-4886.

[29] M.S. Sarwar, Y.H. Jeong, S.H. Chang, Subcooled flow boiling CHF enhancement with porous surface coatings, International journal of heat and mass transfer, 50(17) (2007) 3649-3657.

[30] S. Bhavnani, C.-P. Tsai, R. Jaeger, D. Eison, An integral heat sink for cooling microelectronic components, Journal of Electronic Packaging, 115(3) (1993) 284-291.

[31] J.-Y. Jung, H.-Y. Kwak, Effect of surface condition on boiling heat transfer from silicon chip with submicron-scale roughness, International journal of heat and mass transfer, 49(23) (2006) 4543-4551.

[32] R. Chen, M.-C. Lu, V. Srinivasan, Z. Wang, H.H. Cho, A. Majumdar, Nanowires for enhanced boiling heat transfer, Nano letters, 9(2) (2009) 548-553.

[33] C. Li, Z. Wang, P.I. Wang, Y. Peles, N. Koratkar, G. Peterson, Nanostructured copper interfaces for enhanced boiling, small, 4(8) (2008) 1084-1088.

[34] V. Khanikar, I. Mudawar, T. Fisher, Effects of carbon nanotube coating on flow boiling in a microchannel, International Journal of Heat and Mass Transfer, 52(15) (2009) 3805-3817.

[35] S. Ujereh, T. Fisher, I. Mudawar, Effects of carbon nanotube arrays on nucleate pool boiling, International Journal of Heat and Mass Transfer, 50(19) (2007) 4023-4038.

[36] X. Dai, X. Huang, F. Yang, X. Li, J. Sightler, Y. Yang, C. Li, Enhanced nucleate boiling on horizontal hydrophobic-hydrophilic carbon nanotube coatings, Applied Physics Letters, 102(16) (2013) 161605. 
[37] T.Y. Liu, P. Li, C. Liu, C. Gau, Boiling flow characteristics in microchannels with very hydrophobic surface to super-hydrophilic surface, International Journal of Heat and Mass Transfer, 54(1) (2011) 126134.

[38] A.S. Kousalya, C.N. Hunter, S.A. Putnam, T. Miller, T.S. Fisher, Photonically enhanced flow boiling in a channel coated with carbon nanotubes, Applied Physics Letters, 100(7) (2012) 071601.

[39] F. Yang, X. Dai, Y. Peles, P. Cheng, C. Li, Can multiple flow boiling regimes be reduced into a single one in microchannels?, Applied Physics Letters, 103(4) (2013) 043122.

[40] F. Yang, X. Dai, Y. Peles, P. Cheng, J. Khan, C. Li, Flow boiling phenomena in a single annular flow regime in microchannels (I): Characterization of flow boiling heat transfer, International Journal of Heat and Mass Transfer, 68 (2014) 703-715.

[41] F. Yang, X. Dai, Y. Peles, P. Cheng, J. Khan, C. Li, Flow boiling phenomena in a single annular flow regime in microchannels (II): Reduced pressure drop and enhanced critical heat flux, International Journal of Heat and Mass Transfer, 68 (2014) 716-724.

[42] Y. Peles, S. Haber, A steady state, one dimensional, model for boiling two phase flow in triangular micro-channel, International Journal of Multiphase Flow, 26(7) (2000) 1095-1115.

[43] S.G. Kandlikar, Heat transfer mechanisms during flow boiling in microchannels, in: ASME 2003 1st International Conference on Microchannels and Minichannels, American Society of Mechanical Engineers, 2003, pp. 33-46.

[44] J. Thome, V. Dupont, A. Jacobi, Heat transfer model for evaporation in microchannels. Part I: presentation of the model, International Journal of Heat and Mass Transfer, 47(14) (2004) 3375-3385.

[45] V. Dupont, J. Thome, A. Jacobi, Heat transfer model for evaporation in microchannels. Part II: comparison with the database, International Journal of Heat and Mass Transfer, 47(14) (2004) 33873401.

[46] M.J. Miner, P.E. Phelan, B.A. Odom, C.A. Ortiz, An experimental investigation of pressure drop in expanding microchannel arrays, Journal of Heat Transfer, 136(3) (2014) 031502.

[47] L. Yin, L. Jia, P. Guan, F. Liu, Evaporating momentum force and shear force on meniscuses of elongated bubble in microchannel flow boiling, Journal of Thermal Science, 23(2) (2014) 160-168.

[48] S.G. Kandlikar, Scale effects on flow boiling heat transfer in microchannels: A fundamental perspective, International Journal of Thermal Sciences, 49(7) (2010) 1073-1085.

[49] C. Costello, W. Frea, A salient nonhydrodynamic effect on pool boiling burnout of small semicylindrical heaters, in: AIChE Chemical Engineering Progress Symposium Series, 1963, pp. 258-268.

[50] H.T. Phan, N. Caney, P. Marty, S. Colasson, J. Gavillet, Flow Boiling of Water on Titanium and Diamond-like carbon coated Surfaces in a Microchannel, in: 2010 14th International Heat Transfer Conference, American Society of Mechanical Engineers, 2010, pp. 127-132.

[51] V.K. Dhir, H.S. Abarajith, D. Li, Bubble dynamics and heat transfer during pool and flow boiling, Heat transfer engineering, 28(7) (2007) 608-624.

[52] S.G. Kandlikar, M.E. Steinke, Contact angles of droplets during spread and recoil after impinging on a heated surface, Chemical Engineering Research and Design, 79(4) (2001) 491-498.

[53] T. Harirchian, S.V. Garimella, Flow regime-based modeling of heat transfer and pressure drop in microchannel flow boiling, International Journal of Heat and Mass Transfer, 55(4) (2012) 1246-1260.

[54] W. Qu, I. Mudawar, Flow boiling heat transfer in two-phase micro-channel heat sinks-I. Experimental investigation and assessment of correlation methods, International Journal of Heat and Mass Transfer, 46(15) (2003) 2755-2771.

[55] W. Qu, I. Mudawar, Flow boiling heat transfer in two-phase micro-channel heat sinks-II. Annular two-phase flow model, International Journal of Heat and Mass Transfer, 46(15) (2003) 2773-2784.

[56] H.T. Phan, N. Caney, P. Marty, S. Colasson, J. Gavillet, Surface wettability control by nanocoating: the effects on pool boiling heat transfer and nucleation mechanism, International Journal of Heat and Mass Transfer, 52(23) (2009) 5459-5471. 
[57] B.T. Holcomb, T. Harirchian, S.V. Garimella, An experimental investigation of microchannel size effects on flow boiling with de-ionized water, in: ASME 2009 Heat Transfer Summer Conference collocated with the InterPACKO9 and 3rd Energy Sustainability Conferences, American Society of Mechanical Engineers, 2009, pp. 897-905.

[58] T. Alam, P.S. Lee, C.R. Yap, L. Jin, K. Balasubramanian, Experimental investigation and flow visualization to determine the optimum dimension range of microgap heat sinks, International Journal of Heat and Mass Transfer, 55(25) (2012) 7623-7634.

[59] T. Harirchian, S.V. Garimella, Effects of channel dimension, heat flux, and mass flux on flow boiling regimes in microchannels, International Journal of Multiphase Flow, 35(4) (2009) 349-362.

[60] M.E. Steinke, S.G. Kandlikar, An experimental investigation of flow boiling characteristics of water in parallel microchannels, Journal of Heat Transfer, 126(4) (2004) 518-526.

[61] S.S. Bertsch, E.A. Groll, S.V. Garimella, Effects of heat flux, mass flux, vapor quality, and saturation temperature on flow boiling heat transfer in microchannels, International Journal of Multiphase Flow, 35(2) (2009) 142-154. 